Bundesgesundheitsbl 2018 $\cdot 61: 874-893$ https://doi.org/10.1007/s00103-018-2766-3 (c) Springer-Verlag GmbH Deutschland, ein Teil von Springer Nature 2018

Mitteilungen des Arbeitskreises Blut des Bundesministeriums für Gesundheit

\title{
Pathogen-Inaktivierungssysteme für Thrombozytenkonzentrate
}

\section{Stellungnahme}

Bei der 85. Sitzung des Arbeitskreises Blut am 17./18.04.2018 wurde folgende Stellungnahme (S 18) verabschiedet:

\section{Allgemeine Einleitung und Problemstellung}

Das Auftreten neuer Infektionskrankheiten oder die Ausbreitung von identifizierten Erregern außerhalb der bekannten Endemiegebiete kann die Transfusionssicherheit beeinträchtigen. Bislang wurden in solchen Fällen Testmethoden adaptiert oder Spenderauswahlkriterien verändert, um infizierte Spender zu entdecken und von der Spende auszuschließen. Diese reaktive Strategie erfolgte meistens mit einer zeitlichen Verzögerung. Die Anwendung von Inaktivierungsmethoden könnte die Sicherheit von Blutkomponenten hinsichtlich dieser Risiken verbessern. Die Vorteile und Grenzen dieser Verfahren sollen gegen mögliche unerwünschte Reaktionen und Einschränkungen der Produktqualität abgewogen werden.

Der Begriff Pathogeninaktivierung wird für Methoden verwendet, die die Infektiosität von Pathogenen durch chemische Reaktion oder durch physikalische Einflüsse (z. B. UV-Licht) zerstören. Der Begriff suggeriert, dass kein Pathogen die Behandlung überstehen kann. Liegt jedoch eine hohe Pathogen-Kontamination vor oder ist das Pathogen nicht empfindlich gegenüber dem spezifischen Verfahren, kann es sein, dass die Inaktivierungskapazität des Verfahrens nicht ausreicht. Es wäre deshalb besser von einer Pathogenreduktion zu sprechen. Im deutschen Sprachgebrauch hat sich jedoch der Begriff Pathogeninaktivierung (PI) etabliert, so dass er auch durchgehend in dieser Stellungnahme verwendet wird.
In den vergangenen Jahren wurden verschiedene Methoden der PI für Blutkomponenten entwickelt; einige Systeme haben bereits ein CE-Kennzeichen erhalten und sind damit innerhalb der EU verkehrsfähig. In Deutschland ist darüber hinaus eine Zulassung für die mit einem solchen System behandelten Blutkomponenten erforderlich. Die Systeme wurden in klinischen Studien getestet und werden mittlerweile in einigen Ländern eingesetzt [1-5]. Es wird jedoch diskutiert, ob die angewandten Inaktivierungsmethoden klinisch relevante Veränderungen an den zellulären oder plasmatischen Bestandteilen der Blutkomponenten hervorrufen, die zu verminderter Wirksamkeit oder Unverträglichkeit führen bzw. Immunreaktionen induzieren können.

Grundsätzlich zielen alle diese $\mathrm{Me}$ thoden auf die Inaktivierung von Nukleinsäuren von Pathogenen. Sie sind daher nur für die Inaktivierung von DNA- oder RNA-haltigen Pathogenen, nicht aber infektiösen Proteinen wie Prionen geeignet. Sie können nur für Blutkomponenten eingesetzt werden, die keine kernhaltigen Zellen als Wirkstoff enthalten, wie Erythrozytenkonzentrate (EK), Thrombozytenkonzentrate (TK) und therapeutisches Plasma.

In dieser Stellungnahme werden nur Systeme berücksichtigt, die eine CEKennzeichnung erhalten haben [6] und für die routinemäßige Anwendung zur Behandlung von Thrombozytenkonzentraten zur Verfügung stehen bzw. die gegenwärtig in klinischen Prüfungen untersucht werden.

Die Daten aus den Hämovigilanzberichten 2013/14 und 2015 [7, 8] zeigen, dass in Deutschland sowohl das Risiko einer Übertragung von viralen Erregern als auch das Risiko einer Transfusions-bedingten bakteriellen Infektion durch TK [9] sehr gering ist. In einem Zeitraum von vier Jahren (2012-2015) wurden 2,02 Millionen TK-Einheiten in Deutschland transfundiert. Die Melderaten der einzelnen Reaktionen ergeben sich aus der An-

\begin{tabular}{|c|c|}
\hline \multicolumn{2}{|c|}{ Abkürzungen } \\
\hline ATCC & $\begin{array}{l}\text { American Type Culture } \\
\text { Collection }\end{array}$ \\
\hline ATK & $\begin{array}{l}\text { Apherese-Thrombozyten- } \\
\text { konzentrat/e }\end{array}$ \\
\hline $\mathrm{CCl}$ & Corrected count increment \\
\hline$C E$ & $\begin{array}{l}\text { CE-Kennzeichnung nach } \\
\text { REGULATION (EU) 2017/745 [6] }\end{array}$ \\
\hline$D S M$ & $\begin{array}{l}\text { Deutsche Sammlung für Mik- } \\
\text { roorganismen und Zellkulturen } \\
\text { (Leibniz-Institut) }\end{array}$ \\
\hline EK & Erythrozytenkonzentrat/e \\
\hline HPLC & $\begin{array}{l}\text { High Performance Liquid } \\
\text { Chromatography }\end{array}$ \\
\hline $\begin{array}{l}\text { INTER- } \\
\text { CEPTT }\end{array}$ & INTERCEPT ${ }^{\mathrm{TM}}$ Blood System \\
\hline$I S B T$ & $\begin{array}{l}\text { International Society for Blood } \\
\text { Transfusion }\end{array}$ \\
\hline$L R F$ & log10 Reduktionsfaktor/en \\
\hline MIRASOL ${ }^{\oplus}$ & $\begin{array}{l}\text { MIRASOL }^{\oplus} \text { Pathogen Reduction } \\
\text { Technology System }\end{array}$ \\
\hline PBMC & $\begin{array}{l}\text { Peripheral Blood Mononuclear } \\
\text { Cells }\end{array}$ \\
\hline$P I$ & Pathogeninaktivierung \\
\hline PTK & Pool-Thrombozytenkonzentrat/e \\
\hline$T A-G v H D$ & $\begin{array}{l}\text { Transfusions-assoziierte Graft- } \\
\text { versus-Host-Disease }\end{array}$ \\
\hline$T B B I$ & $\begin{array}{l}\text { Transfusionsbedingte Bakterielle } \\
\text { Infektionen }\end{array}$ \\
\hline THERAFLEX & THERAFLEX UV-Platelets system \\
\hline$T K$ & Thrombozytenkonzentrat/e \\
\hline WHO & World Health Organization \\
\hline
\end{tabular}




\begin{tabular}{|c|c|}
\hline \multicolumn{2}{|c|}{ Abkürzungen Viren } \\
\hline$A d V-5$ & Adenovirus Typ 5 \\
\hline B19V & Parvovirus B19 \\
\hline$B F V$ & Barmah Forest Virus \\
\hline BoHV-1 & Bovines Herpesvirus 1 (IBR) \\
\hline BTV-11 & Bluetongue Virus 11 \\
\hline$B V D V$ & Bovines Virusdiarrhoe-Virus \\
\hline CHIKV & Chikungunya-Virus \\
\hline DENV & Dengue-Virus $(-1,-2,-3,-4)$ \\
\hline$D H B V$ & Duck Hepatitis B Virus \\
\hline$E M C V$ & Encephalomyocarditis-Virus \\
\hline HAV & Hepatitis A Virus \\
\hline$H B V$ & Hepatitis B Virus \\
\hline HCMV & Humanes Cytomegalovirus \\
\hline $\mathrm{HCV}$ & Hepatitis C Virus \\
\hline$H I V-1 /-2$ & $\begin{array}{l}\text { Humanes Immundefizienz-Virus } \\
1 / 2\end{array}$ \\
\hline$H T L V-I /-I I$ & $\begin{array}{l}\text { Humanes T-lymphotropes Virus } \\
1 / 2\end{array}$ \\
\hline LACV & La Crosse-Virus \\
\hline MCMV & Murines Cytomegalovirus \\
\hline MVEV & Murrey Valley Encephalitis-Virus \\
\hline PPV & Porcines Parvovirus \\
\hline PRV & Pseudorabiesvirus (SuHV-1) \\
\hline RRV & Ross River Virus \\
\hline SARS-CoV & $\begin{array}{l}\text { Severe Acute Respiratory } \\
\text { Syndrome Coronavirus }\end{array}$ \\
\hline SFTSV & $\begin{array}{l}\text { Severe Fever with Thrombocyto- } \\
\text { penia Syndrome Virus }\end{array}$ \\
\hline SHV 1 & Suid Herpesvirus 1 (SuHV-1/PRV \\
\hline SINV & Sindbisvirus \\
\hline VSV & Vesikuläres Stomatitis-Virus \\
\hline WNV & West-Nil-Virus \\
\hline ZIKV & Zika-Virus \\
\hline
\end{tabular}

zahl bestätigter Transfusionsreaktionen bezogen auf $10^{6}$ transfundierte TK-Einheiten (• Tab. 1). Allerdings ist hierbei zu berücksichtigen, dass einige Spendeeinrichtungen bereits zusätzlich zu den angeordneten Auflagen auf freiwilliger Basis Maßnahmen zur Reduktion von bakteriellen Infektionen durchführen (z. B. Testung der Produkte) und somit die Häufigkeit dieser Übertragungen mutmaßlich bereits reduziert ist.

Die Daten beziehen sich auf Erreger, die bekannt sind und die durch Spendertestung nachgewiesen werden bzw. nachgewiesen werden könnten. Beim Auf- treten neuer Erreger ist ein mögliches Übertragungsrisiko anders einzuschätzen. Vor allem für diesen Fall könnte die PI die Sicherheit von Blutkomponenten weiter erhöhen, sofern der Erreger für das angewandte PI-Verfahren empfindlich ist.

Des Weiteren führt die PI zu einer Inaktivierung der noch im Präparat befindlichen Leukozyten, so dass nach PI eine Bestrahlung der Präparate mit 30 Gy zur Vermeidung einer Graft versus Host $(\mathrm{GvH})$ Reaktion bei entsprechender Indikation entfallen kann.

\section{Inaktivierungsmethoden}

Aktuell haben in Deutschland drei Systeme zur Pathogeninaktivierung von Thrombozytenkonzentraten eine CEKennzeichnung: INTERCEPT ${ }^{\mathrm{TM}}$, MIRASOL ${ }^{\circledR}$ und THERAFLEX. Aufgrund ihrer unterschiedlichen Wirkmechanismen werden sie im Folgenden zunächst separat beschrieben. Die überwiegende Mehrheit der heute zur Verfügung stehenden Daten zur Inaktivierungskapazität und aus klinischen Studien wurden von den Herstellern oder in Zusammenarbeit mit den Herstellern veröffentlicht.

\subsection{INTERCEPT ${ }^{\mathrm{TM}}$ Blood System (Amotosalen/UVA)}

Das INTERCEPT ${ }^{\mathrm{TM}}$ Blood System (CERUS Europe BV, Amersfoort, Niederlande; CERUS Corp., Concord, CA, USA) wurde für die Inaktivierung von Pathogenen in Thrombozyten- und PlasmaPräparaten entwickelt. Es erhielt 2002 die CE-Kennzeichnung für TK und 2006 für Plasma [10] und wird gegenwärtig in 22 Ländern routinemäßig angewendet [1, $11,12]$.

\subsubsection{Wirkmechanismus und Inaktivierungskapazität}

Das INTERCEPT ${ }^{\mathrm{TM}}$ Blood System (INTERCEPT $\left.^{\mathrm{TM}}\right)$ verwendet Amotosalen-HCl (3-(2-aminoethoxymethyl)-2, 5,9-trimethylfuro[3,2-g]chromen-7-one hydrochlorid, $\mathrm{C}_{17} \mathrm{H}_{20} \mathrm{ClNO}_{4}$ ). Amotosalen, auch S-59 genannt, ist eine PsoralenVerbindung mit hoher Affinität zu Nukleinsäuren [13]. Es durchdringt Zellwände, Kernmembranen und z.B. die Lipidhülle von Viren und lagert sich in die Nukleinsäure ein [14].

Die Reaktion, die letztendlich zur Inaktivierung führt, erfolgt in drei Stufen: (1) die Einlagerung von Amotosalen in helikale Regionen des Genoms, (2) die Ausbildung einer kovalenten Bindung von Amotosalen mit einer Pyrimidinbase im Genom und (3) die UVA induzierte Vernetzung (Interstrang crosslinking) durch Reaktion mit einer Pyrimidinbase eines zweiten Stranges [15]. Unter typischen Reaktionsbedingungen liegen mehr als $50 \%$ der Addukte strangvernetzt vor [16]. Durch die Strangvernetzung wird eine Transkription bzw. Replikation der DNA/RNA verhindert. Wegen der hohen Vernetzungsdichte sind DNA-Reparaturmechanismen wirkungslos.

Die Photoreaktion von Amotosalen mit Nukleinsäuren ist nicht sequenz-spezifisch. Die Reaktion erfolgt bevorzugt mit den Pyrimidinbasen Thymidin und Cytidin; eine Reaktion mit Uracil ist sechs- bis achtmal langsamer [17]. Die Bildung von Psoralen-Nukleotid-Addukten ist hochspezifisch und erfolgt auch bei z. B. geringer Konzentration von Pathogenen und einem Überschuss von Plasmaproteinen oder Thrombozyten. Interstrang-Reaktionen sind möglich, so dass ein breites Spektrum von Nukleinsäuren einschließlich der von Viren und anderen Pathogenen inaktiviert werden kann [10]. Auch Einzelstranggenome haben sekundäre Strukturen, z. B. hairpin turns und loops, bei denen durch die Paarung von kurzen Genomabschnitten doppelsträngige $\mathrm{Ab}$ schnitte entstehen, die die Einlagerung und Vernetzung von Genomabschnitten mit Amotosalen erlauben und damit die Inaktivierung bewirken.

Amotosalen wird durch Photonen zur Bindung angeregt; bei Bestrahlung löst es eine photochemische Typ I oder Typ II Reaktion aus; beide führen zur Ausbildung von reactive oxygen species (ROS). Obwohl die hauptsächliche Bindungsaffinität von Amotosalen zu Nukleinsäuren besteht, sind durch Bildung von Radikalen auch Reaktionen mit anderen Molekülen, z. B. Aminosäuren, möglich [17]. Die Bedeutung dieser Ergebnisse im Kontext zu der durch INTERCEPT ${ }^{\mathrm{TM}}$ verursachten, in vitro beobachteten Beeinträchtigung von Thrombozytenfunktion und -meta- 
Tab. 1 Meldungen Transfusions-bedingter Infektionsübertragungen 2012-2015, Allergi-

sche Transfusionsreaktionen Grad III und IV zum Vergleich

\begin{tabular}{|c|c|c|}
\hline Transfusionsreaktion & N Fälle (Todesfälle) & $N$ Fälle pro $10^{6} \mathrm{TK}$ \\
\hline HIV & 0 & 0 \\
\hline $\mathrm{HCV}$ & 0 & 0 \\
\hline HBV & 1 & 0,5 \\
\hline HEV & 4 & 2,0 \\
\hline Bakterielle Infektion ${ }^{a}$ & $10(1)$ & 4,9 \\
\hline Vergleich: ATR III/IV & $108(1)$ & 53,4 \\
\hline
\end{tabular}

bolismus oder der möglichen in vivo Auswirkungen muss noch weiter untersucht werden [18].

INTERCEPT $^{\mathrm{TM}}$ ist nicht geeignet für eine PI in EK oder Vollblut, da das in den Erythrozyten vorhandene Hämoglobin das UVA-Licht absorbiert und somit die kovalenten Bindungen mit Nukleinsäuren nicht oder nur unzureichend ausgebildet werden. Entsprechend muss ein definierter maximaler Erythrozytengehalt eingehalten werden.

Die Inaktivierung von Pathogenen wurde umfangreich untersucht $[13,19-$ 34]. Die Daten sind in den von CERUS Corp. publizierten Produktübersichten dargestellt $[35,36]$. - Tab. 2 fasst die Ergebnisse zusammen. Teilweise sind in der Tabelle die Original-Studienberichte als Referenz hinzugefügt und ergänzende Untersuchungen zusätzlich aufgeführt, wenn sie nicht in der Zusammenfassung von CERUS Corp. enthalten sind. Die Angaben der Inaktivierung in Plasma ergänzen die Datenbasis.

Eine hohe Wirksamkeit (LRF $\geq 5$ ) wurde für nahezu alle untersuchten Viren gezeigt. Eine Ausnahme bilden einige nichtumhüllte Viren, wie Calicivirus, HAV und Parvovirus (B19V und PPV). Das dem Calicivirus ähnliche Hepatitis E Virus (HEV) ist ebenfalls resistent gegenüber der Inaktivierung durch INTERCEPT ${ }^{\mathrm{TM}}$. In einem Fallbericht wurde die Übertragung von HEV durch Transfusion von INTERCEPT $^{\text {TM}}$-inaktiviertem Plasma auf zwei Patienten berichtet [37]. Ohne spezifische Testung findet sich in einer von 679 bis 4252 Spenden HEV RNA [38-41]. Die Wirksamkeit des Verfahrens gegen die Arboviren DENV und ZIKV ist bislang nur in Plasma untersucht worden. Hier konnte ein LRF von 5,6 (DENV) bzw. 6,4 (ZIKV) nachgewiesen werden $[33,34]$.

Während für die meisten Bakterien und Protozoen eine hohe Wirksamkeit für die Inaktivierung gezeigt werden konnte (LRF von $\geq 5 \log _{10}$ ), bilden $P$. aeruginosa bzw. B. cereus hier eine Ausnahme, da bei diesen Erregern ein LRF von 4,5 bzw. 3,6 erreicht wurde. Während sporenbildende Bakterien im vegetativen Zustand empfindlich gegenüber einer Inaktivierung sind, sind bakterielle Sporen gegen diese resistent [35]. Eine Übersicht gibt - Tab. 3.

Um zu verhindern, dass sich im Blutprodukt enthaltene Bakterien während der Lagerung der Blutkomponenten vermehren, sollte die Inaktivierung möglichst früh nach Spende durchgeführt werden [42] und eine vollständige Inaktivierung sichern. Die Inaktivierung von Bakterien (S. aureus, S. epidermidis, S. agalactiae, K. pneumoniae, E. coli, $P$. acnes, C. perfringens) in TK wurde deshalb zusätzlich zur hohen Belastung, wie in $\bullet$ Tab. 3 dargestellt, auch mit geringer Belastung ( 1 bis $1000 \mathrm{CFU} / \mathrm{TK})$ untersucht. In den mit INTERCEPT $^{\mathrm{TM}}$ behandelten TK waren nach Lagerung über maximal 5 Tage keine Bakterien nachzuweisen [30, 43, 44].

Die Inaktivierung von Protozoen durch PI mit INTERCEPT ${ }^{\mathrm{TM}}$ ist in $\bullet$ Tab. 4 dargestellt.

Die PI mit INTERCEPT ${ }^{\mathrm{TM}}$ ist eine Alternative zur Inaktivierung von Leukozyten durch Gammabestrahlung von TK für die Prävention einer transfusions-assoziierten Graft-versus-Host Reaktion (TA-GvHD) [36]. Nukleinsäuren der in den TK enthaltenen restlichen Leukozyten werden durch die Behandlung effektiv geschädigt, so dass Proliferation und Pro- teinsynthese unterbunden werden, gezeigt mittels PCR Amplification Inhibition Assay, Limiting Dilution Analysis und als Inhibition der Zytokinsynthese (u.a. IL-8) in Leukozyten [45]. In einem standardisierten „parent to F1“ Transfusions-Mäusemodell wurden über 10 Wochen nach Transfusion alle labordiagnostischen, klinischen und histologischen Parameter zum Nachweis einer GvHD gemessen. Es konnte gezeigt werden, dass die Amotosalen/UVA-Behandlung eine GvH-Reaktion durch Spenderlymphozyten verhindert [46].

Der Wirkmechanismus und die Wirksamkeit der Pathogeninaktivierung in TK durch INTERCEPT ${ }^{\mathrm{TM}}$ lassen sich in folgenden Punkten zusammenfassen:

INTERCEPT ${ }^{\mathrm{TM}}$ benutzt Amotosalen$\mathrm{HCl}$, ein synthetisches Psoralen-Derivat.

- Die Inaktivierung von Pathogenen in

TK mit INTERCEPT ${ }^{\mathrm{TM}}$ erfolgt durch Bindung von Amotosalen an Nukleinsäuren, Ausbildung der kovalenten Bindung mit einer Pyrimidinbase und irreversible Vernetzung durch Reaktion mit der Pyrimidinbase eines zweiten Stranges. Um seine Wirkung zu entfalten, muss Amotosalen mit Nukleinsäuren in Kontakt kommen, also Zellwände, Kapside etc. durchdringen können. Die Reaktion von Amotosalen mit Nukleinsäuren ist nicht sequenz-spezifisch.

- Die Vernetzung von Nukleinsäuren mit Amotosalen erfolgt durch Energieaufnahme bei Bestrahlung (mit UVA $320-400 \mathrm{~nm}, 3 \mathrm{~J} / \mathrm{cm}^{2}$ ).

- Vorliegende Daten bestätigen, dass INTERCEPT ${ }^{\mathrm{TM}}$ ein großes Spektrum von Pathogenen inaktiviert; es hat eine

- hohe Wirksamkeit zur Inaktivierung von umhüllten Viren,

- eingeschränkte oder keine Wirksamkeit für die Inaktivierung einiger nicht-umhüllter Viren, HAV, Parvovirus (B19V und PPV) und HEV

- hohe Wirksamkeit zur Inaktivierung von Protozoen und Bakterien, wobei Sporen stabiler sind und wahrscheinlich nicht vollständig inaktiviert werden. Der Zeitraum zwischen Blutentnahme und Durchführung der Inaktivierung 


\begin{tabular}{|c|c|c|c|c|}
\hline INTERCEPT ${ }^{\mathrm{TM}}:$ VIREN & $\begin{array}{l}\text { TK in Plasma mit } \\
\text { Additivlösung }\end{array}$ & TK in Plasma & Plasma & Referenzen \\
\hline \multicolumn{5}{|l|}{ VIREN, mit Lipidhülle } \\
\hline \multirow[t]{2}{*}{ BVDV (Modell für HCV) } & $\geq 6,0$ & $\geq 5,4$ & $\geq 6,0$ & {$[35,36]$} \\
\hline & $\mathrm{kA}$ & $\geq 6,03$ & $\mathrm{kA}$ & [32] \\
\hline CHIKV & $\geq 6,4$ & $\geq 7,6$ & $\geq 7,6$ & {$[35,36]$} \\
\hline HCMV (intrazellulär) & $\geq 5,9$ & $\mathrm{kA}$ & $\mathrm{kA}$ & {$[32,35,36]$} \\
\hline DENV & $\mathrm{kA}$ & $\mathrm{kA}$ & $\geq 5,6$ & [33] \\
\hline DHBV & $\geq 6,2$ & $4,4-4,5$ & $4,4-4,5$ & {$[35,36]$} \\
\hline HBV & $\geq 5,5$ & $\geq 4,5$ & $\geq 4,5$ & {$[35,36]$} \\
\hline $\mathrm{HCV}$ & $\geq 4,5$ & $\geq 4,5$ & $\geq 4,5$ & {$[35,36]$} \\
\hline \multirow[t]{2}{*}{ HIV-1 (zellfrei) } & $\geq 6,2$ & $\geq 4,7$ & $\geq 6,8$ & {$[35,36]$} \\
\hline & $\geq 4,2$ & $\mathrm{kA}$ & $\mathrm{kA}$ & {$[32]$} \\
\hline HIV-1 (klinisches Isolat) & $\geq 3,4$ & $\mathrm{kA}$ & $\mathrm{kA}$ & {$[35,36]$} \\
\hline HIV-1 (intrazellulär) & $\geq 6,1$ & $\geq 6,7$ & $\geq 6,7$ & {$[35,36]$} \\
\hline HIV-2 (klinisches Isolat) & $\geq 2,5$ & $\mathrm{kA}$ & $\mathrm{kA}$ & {$[35,36]$} \\
\hline HTLV-I (intrazellulär) & 4,7 & $\geq 4,5$ & $\geq 4,5$ & {$[35,36]$} \\
\hline HTLV-II (intrazellulär) & 5,1 & $\geq 5,7$ & $\geq 5,7$ & {$[35,36]$} \\
\hline Influenza $\mathrm{A}\left(\mathrm{H}_{5} \mathrm{~N}_{1}\right)$ & $\geq 5,9$ & $\geq 5,7$ & $\geq 5,7$ & {$[35,36]$} \\
\hline \multirow[t]{2}{*}{ PRV } & $\mathrm{kA}$ & $\geq 4,7$ & $\mathrm{kA}$ & {$[35,36]$} \\
\hline & & $\geq 5,2$ & & {$[32]$} \\
\hline \multirow[t]{2}{*}{ SARS-CoV } & $\mathrm{kA}$ & $\geq 5,5$ & $\geq 5,5$ & {$[35,36]$} \\
\hline & $\geq 6,2$ & $\mathrm{kA}$ & $\mathrm{kA}$ & {$[26]$} \\
\hline \multirow[t]{2}{*}{ WNV } & $\geq 6,0$ & $\geq 6,8$ & $\geq 6,8$ & {$[35,36]$} \\
\hline & $\geq 5,2$ & $\mathrm{kA}$ & $\mathrm{kA}$ & {$[27]$} \\
\hline ZIKV & $\mathrm{kA}$ & $\mathrm{kA}$ & $\geq 6,5$ & [34] \\
\hline \multicolumn{5}{|l|}{ VIREN, ohne Lipidhülle } \\
\hline BTV-11 & $\geq 5,0$ & 5,1 & 5,1 & {$[35,36]$} \\
\hline Calicivirus $^{\mathrm{b}}$ & $1,7-2,4$ & $\mathrm{kA}$ & $\mathrm{kA}$ & {$[35,36]$} \\
\hline AdV 5 & $\geq 5,9$ & $\geq 6,9$ & $\geq 6,9$ & {$[35,36]$} \\
\hline HAV & 0,76 & $\mathrm{kA}$ & $\mathrm{kA}$ & {$[32]$} \\
\hline PPV & 0,38 & $\mathrm{kA}$ & $\mathrm{kA}$ & {$[32]$} \\
\hline B19V & $\mathrm{kA}$ & 1,8 & 1,8 & {$[35,36]$} \\
\hline \multicolumn{5}{|c|}{$\begin{array}{l}k A \text { keine Angaben } \\
{ }^{\mathrm{L}} \mathrm{LRF} \geq \text { bedeutet, dass im Experiment eine vollständige Inaktivierung erreicht wurde. Die Zahl gibt die Nach- } \\
\text { weisgrenze an. } \\
{ }^{b} \text { Virus nicht spezifiziert }\end{array}$} \\
\hline
\end{tabular}

sollte kurz sein und muss definiert werden.

- INTERCEPT ${ }^{\mathrm{TM}}$ ist wirksam für die Inaktivierung von Leukozyten: Proliferation und Proteinsynthese werden unterbunden, die Methode wird als Alternative zur Gammabestrahlung gesehen. Außerdem wird die Antigenpräsentation vermindert und die Ausder Lagerung gehemmt.

\subsubsection{Unerwünschte Effekte der Pathogeninaktivierung mit INTERCEPT ${ }^{\mathrm{TM}}$}

Unerwünschte Effekte der PI von TK mit INTERCEPT ${ }^{\mathrm{TM}}$ betreffen mögliche toxische Effekte des Amotosalens, Bildung schüttung von Zytokinen während von Neo-Antigenen, Veränderungen von in-vitro Stoffwechsel- und Funktionsparametern, Einflüsse auf die messenger-RNA (mRNA) bzw. micro-RNA (mi-RNA) sowie das Proteom der Thrombozyten und einen Verlust an Thrombozyten durch das Herstellungsverfahren.

Um mögliche genotoxische Effekte $\mathrm{zu}$ vermeiden, werden restliches Amotosalen und ungebundene Photoderivate nach der photochemischen Behandlung durch Inkubation in einem compound adsorption device weitgehend vor der Anwendung aus dem TK entfernt. Die Sicherheit von Amotosalen als Reinsubstanz wurde mittels in-vitro Tests geprüft. Es zeigte sich dabei mutagen für $S$. $t y$ phimurium und Mauslymphoma Zellen sowie klastogen für Zellen aus einer Hamster-Ovarzelllinie (CHO-Zellen). Im Maus-Knochenmark-Mikronukleus-Test und im Ratten-HepatozytenUDS(unscheduled DNA synthesis)-Test zeigte Amotosalen hingegen auch in toxischen Dosen keine mutagene Wirkung. Amotosalen sowie INTERCEPT ${ }^{\mathrm{TM}}-\mathrm{TK}$ und INTERCEPT ${ }^{\mathrm{TM}}$-Plasma wurden zusätzlich in pharmakokinetischen und toxikologischen Studien in verschiedenen Nagern, Hunden und Primaten geprüft. Es ergaben sich weder in pharmakologischen Studien zur akuten und chronischen Toxizität (ZNS, kardiovaskuläres und renales System) noch in Studien zur Genotoxizität oder Reproduktionstoxizität Hinweise auf schädliche Wirkungen. In einem p53 knock out Mausmodell (Karcinogenitätstest) mit dem $1000 \mathrm{fa}$ chen der erwarteten Humandosis entwickelte innerhalb von 39 Wochen keines der Tiere Tumore. Aus den Ergebnissen der pharmakokinetischen und toxikologischen Studien kann geschlossen werden, dass die Amotosalen/UVA-Behandlung von TK keine erkennbaren toxikologischen Risiken für den Menschen birgt [10, 47].

Die Bildung von Neo-Antigenen in den INTERCEPT ${ }^{\mathrm{TM}}$-TK wurde in Seren von 523 Patienten aus 7 klinischen Studien der Phase III, die insgesamt mehr als 8000 Einheiten INTERCEPT ${ }^{\mathrm{TM}_{\text {}}}$-TK oder INTERCEPT ${ }^{\text {TM }}$-Plasma erhalten hatten, untersucht. Dabei konnten keine Antikörper gegen potenzielle Neo-Antigene nachgewiesen werden [48]. 
Tab. 3 Inaktivierung von Bakterien mit INTERCEPT ${ }^{\mathrm{TM}}$. Die Inaktivierungskapazität ist als logarithmischer Faktor der Abnahme der Vermehrungsfähigkeit ( $\log _{10}$ Reduktionsfaktor, LRF) dargestellt

\begin{tabular}{|c|c|c|c|c|}
\hline INTERCEPT TM: BAKTERIEN & $\begin{array}{l}\text { TK in Plasma mit } \\
\text { Additivlösung }\end{array}$ & TK in Plasma & Plasma & Referenzen \\
\hline \multicolumn{5}{|l|}{ BAKTERIEN, gram-negativ } \\
\hline Anaplasma phagocytophilum & - & $\geq 4,2$ & $\geq 4,2$ & {$[35,36]$} \\
\hline Borrelia burgdorferi & $\geq 6,8 ; \geq 6,9$ & $\geq 10,6$ & $\geq 10,6$ & {$[22,35,36]$} \\
\hline Enterobacter cloacae & 5,9 & $\mathrm{kA}$ & $\mathrm{kA}$ & {$[22,35,36]$} \\
\hline Escherichia coli & $\geq 6,4$ & $\geq 7,3$ & - & {$[22,35,36]$} \\
\hline Klebsiella pneumoniae & $\geq 5,6$ & $\geq 6,7$ & $\geq 7,4$ & {$[22,35,36]$} \\
\hline Pseudomonas aeruginosa & 4,5 & $\mathrm{kA}$ & $\mathrm{kA}$ & {$[22,35,36]$} \\
\hline Salmonella choleraesuis & $\geq 6,2$ & $\mathrm{kA}$ & $\mathrm{kA}$ & {$[22,35,36]$} \\
\hline Serratia marcescens & $\geq 6,7$ & $\mathrm{kA}$ & $\mathrm{kA}$ & {$[22,35,36]$} \\
\hline Treponema pallidum & $\geq 6,8-\geq 7,0$ & $\geq 5,9$ & $\geq 5,9$ & {$[22,35,36]$} \\
\hline Yersinia enterocolitica & $\geq 5,9$ & $\geq 7,3$ & $\geq 7,3$ & {$[22,35,36]$} \\
\hline \multicolumn{5}{|l|}{ BAKTERIEN, gram-positiv } \\
\hline Bacillus cereus (vegetativ+ Sporen) & 3,6 & $\mathrm{kA}$ & $\mathrm{kA}$ & {$[35,36]$} \\
\hline Bacillus cereus (vegetativ) & $\geq 6,0 ; \geq 5,5$ & $\mathrm{kA}$ & $\mathrm{kA}$ & {$[22,35,36]$} \\
\hline Bifidobacterium adolescentis & $\geq 6,5 ; \geq 6,0$ & $\mathrm{kA}$ & $\mathrm{kA}$ & {$[22,35,36]$} \\
\hline Clostridium perfringens & $\geq 7,0 ; \geq 6,5$ & $\mathrm{kA}$ & $\mathrm{kA}$ & {$[22,35,36]$} \\
\hline Corynebacterium minutissimum & $\geq 6,3$ & $\mathrm{kA}$ & $\mathrm{kA}$ & {$[22,35,36]$} \\
\hline Lactobacillus species & $\geq 6,9$ & $\mathrm{kA}$ & $\mathrm{kA}$ & {$[35,36]$} \\
\hline Listeria monocytogenes & $\geq 6,3$ & $\mathrm{kA}$ & $\mathrm{kA}$ & {$[22,35,36]$} \\
\hline Propionibacterium acnes & $\geq 6,7 ; \geq 6,2$ & $\mathrm{kA}$ & $\mathrm{kA}$ & {$[22,35,36]$} \\
\hline Staphylococcus aureus & 6,6 & $\geq 7,6$ & $\mathrm{kA}$ & {$[22,35,36]$} \\
\hline Staphylococcus epidermidis & $\geq 6,6$ & $\geq 7,4$ & $\geq 7,3$ & {$[22,35,36]$} \\
\hline Streptococcus pyogenes & $\geq 6,8$ & $\mathrm{kA}$ & $\mathrm{kA}$ & {$[22,35,36]$} \\
\hline \multicolumn{5}{|c|}{$\begin{array}{l}\text { KA keine Angaben } \\
\text { aLF } \geq \text { bedeutet, dass im Experiment eine vollständige Inaktivierung erreicht wurde. Die Zahl gibt die Nach- } \\
\text { weisgrenze an. }\end{array}$} \\
\hline
\end{tabular}

Die von verschiedenen Arbeitsgruppen untersuchten in-vitro Parameter zeigten unterschiedliche Ergebnisse. Diese sind vor allem auf unterschiedliche Versuchsbedingungen, unterschiedliche Qualität der TK und die schwierige Standardisierbarkeit der Teste mit Thrombozyten unterschiedlicher Spender zurückzuführen.

Insgesamt kann aber festgehalten werden, dass die INTERCEPT ${ }^{\text {TM}}$-Behandlung nur zu einem moderaten Anstieg der anaeroben Energiegewinnung als Folge der Thrombozytenaktivierung führt. Der Anstieg von Lactat und Glukoseverbrauch sowie der Abfall des pH-Werts unterschieden sich über 7 Tage Lagerung in den meisten Studien nicht signifikant von den unbehandelten Kontrollen [49-51].
Der in INTERCEPT TM - TK gemessene Anstieg des Aktivierungsmarkers p-Selektin oder auch die Kollagen- und Thrombin-induzierte Aggregation waren meist erst nach 5 Tagen Lagerung signifikant von den Kontrollen unterschieden $[52,53]$. Die mittels Durchflusszytometrie gemessene Annexin V-Bindung an Phosphatidylserin der Thrombozytenoberfläche, ein Maß für Apoptose, unterschied sich nicht von den Kontrollen [50, 51].

Die Befunde zum Einfluss der INTERCEPT $^{\text {TM }}$-Behandlung auf Funktionsparameter wie hypotone Schockresistenz (hypotonic shock resistance, HSR), Aus$\mathrm{maß}$ des Formwandels (extension of shape change, ESC) und Aggregation sind uneinheitlich. Die beobachteten Unterschiede zu den Kontrollen sind meist gering [49,
50, 53-56]. Signifikante Unterschiede zu den Kontrollen in der Aggregation wurden z.T. nur mit Kollagen und Ristocetin als Agonisten beobachtet, was den Erhalt von sekundären Verstärkungsmechanismen über z.B. ADP vermuten lässt [51]. Ebenso unterscheiden sich die Ergebnisse der Untersuchungen zum Einfluss der INTERCEPT ${ }^{\mathrm{TM}}$-Behandlung auf die Thrombozytenadhäsion, Fibrinogen- und vWF-Rezeptor. Dies ist abhängig u. a. von Menge und Art der Suspensionslösung im Versuchsansatz, vom Messen unter statischen Bedingungen oder von Scherkräften und der Art der Oberflächen [57-59]. Plausibel sind die Befunde zu einer gestörten Aktivierungskette vom Kollagenrezeptor bis zum Fibrinogenrezeptor, infolgedessen die Thrombusbildungsrate irreversibel beeinträchtigt wird [51].

In einem Hämostase-Globaltest (RO$\mathrm{TEM}^{\circ}$ ) war die Gerinnungszeit nach $5 \mathrm{Ta}-$ gen Lagerung verglichen mit den Kontrollen nur leicht verkürzt [60].

Trotz Fehlens eines Zellkerns enthalten Thrombozyten mRNA aus Megakaryozyten. Sie sind daher in begrenztem Umfang zur Proteinsynthese befähigt. Ebenso verfügen Thrombozyten über miRNA, die post-transkriptional die Genexpression beeinflussen und damit die Proteinsynthese regulieren kann. Eine Reihe von Untersuchungen zum Einfluss von INTERCEPT TM ${ }^{\mathrm{TM}}$ auf mRNA, miRNA und das Plättchenproteom zeigen Veränderungen in unterschiedlichem Ausmaß:

In einer vergleichenden Studie wurden nach PI mit INTERCEPT ${ }^{\mathrm{TM}}$ verringerte Spiegel an 6 von 11 untersuchten miRNA und an 2 von 3 anti-apoptotischen mRNA gemessen [61]. Die Autoren konnten keine Quervernetzung der endogenen RNA beobachten und sprechen von einer Deregulation einzelner mRNA. Die Verminderung der miRNA-Spiegel wurde auf deren vermehrte Freisetzung in Mikropartikeln zurückgeführt, was sowohl in TK mit Additivlösung als auch in INTERCEPT TM TK beobachtet werden konnte. Die PITechnologie hatte in dieser Untersuchung keinen Einfluss auf Synthese und Funktion der miRNA.

Dieser Befund wird grundsätzlich gestützt durch Untersuchungen von Bakkour et al. [62], die eine Korrelation zwischen RNA-Länge und Ausmaß der 
Tab. 4 Inaktivierung von Protozoen mit INTERCEPTT ${ }^{\text {TM }}$. Die Inaktivierungskapazität ist als

logarithmischer Faktor der Abnahme der Vermehrungsfähigkeit ( $\log _{10}$ Reduktionsfaktor, LRF) ${ }^{\mathrm{a}}$ dargestellt

\begin{tabular}{|c|c|c|c|c|}
\hline INTERCEPTTM: PROTOZOEN & $\begin{array}{l}\text { TK in Plasma mit } \\
\text { Additivlösung }\end{array}$ & TK in Plasma & Plasma & Referenzen \\
\hline Babesia microti & $\geq 5,3$ & $\geq 5,3$ & $\geq 5,3$ & {$[31,35,36]$} \\
\hline $\begin{array}{l}\text { Leishmania major (JISH 118, amas- } \\
\text { tigote stage) }\end{array}$ & $\geq 4,3$ & $\mathrm{kA}$ & $\mathrm{kA}$ & {$[35,36]$} \\
\hline $\begin{array}{l}\text { Leishmania mexicana (metacyclic } \\
\text { promastigote stage) }\end{array}$ & $\geq 5,0$ & $\mathrm{kA}$ & $\mathrm{kA}$ & {$[24,35,36]$} \\
\hline Plasmodium falciparum & $\geq 6,0$ & $\geq 6,9$ & $\geq 6,9$ & {$[31,35,36]$} \\
\hline Trypanosoma cruzi & $\geq 5,3$ & $\geq 5,0$ & $\geq 5,0$ & {$[35,36]$} \\
\hline \multicolumn{5}{|c|}{$\begin{array}{l}k A \text { keine Angaben } \\
\text { a } L F F \geq \text { bedeutet, dass im Experiment eine vollständige Inaktivierung erreicht wurde. Die Zahl gibt die Nach- } \\
\text { weisgrenze an. }\end{array}$} \\
\hline
\end{tabular}

Schädigung durch INTERCEPT ${ }^{\mathrm{TM}}$ zeigen. Es ist noch offen, welche Bedeutung die vermehrte Freisetzung der miRNA und die Verminderung der mRNA für die Thrombozytenfunktion haben, wobei die Freisetzung von miRNA nach Thrombozytenaktivierung ein bekanntes Phänomen ist, ebenso wie deren Interaktion mit Endothelzellen [63, 64]. Mittels "genome-wide differential expression RNA sequencing" konnte die Arbeitsgruppe um Osman zeigen, dass INTERCEPT ${ }^{\mathrm{TM}}$, z. T. auch die Additivlösung selbst, das mRNA-Transkriptom der TK verändert [65]. Bei etwa $20 \%$ der mit INTERCEPT ${ }^{\mathrm{TM}}$ behandelten TK wurden gegenüber den Kontroll-TK verringerte mRNA-Konzentrationen auf weniger als die Hälfte gefunden. Die Autoren dieser Studien [61, 65] stellen Forschungsbedarf hinsichtlich der Fragen fest, welche Bedeutung die Proteinsynthese für Thrombozyten in einem TK hat, welche Rolle die miRNA für die Regulation der mRNA-Translation und für die Funktion und Reaktivität der Thrombozyten hat sowie welche klinische Relevanz die reduzierten miRNA- und mRNA-Spiegel und die beobachtete Thrombozytenaktivierung in vitro bei gleichzeitig wenig beeinträchtigter TRAP-6- und Kollagen-, nicht aber ADPinduzierter Aggregation haben.

Untersuchungen am Proteom der INTERCEPT $^{\mathrm{TM}_{-}}$TK zeigten Konzentrationsänderungen einzelner Proteine, auch wenn der Anteil der Veränderungen am Gesamtproteom nur gering war. Vor allem Proteine, die an intrazellulären Aktivie- rungswegen beteiligt sind, zeigten qualitative und quantitative Änderungen nach INTERCEPT ${ }^{\mathrm{TM}}$-Behandlung $[66,67]$.

Die Pathogeninaktivierung durch INTERCEPT ${ }^{\mathrm{TM}}$ führt zu einem relevanten Thrombozytenverlust im TK von bis zu $15 \%$ [53, 54]. Für eine adäquate Wirksamkeit von INTERCEPT TM-TK muss daher die Thrombozytenzahl vor der Herstellung höher sein als in StandardTK, um die Verluste durch die PI auszugleichen. Das erfordert ein zusätzliches Buffy coat für PTK und erlaubt in der Regel die Entnahme von höchstens 2 ATK pro Apherese.

Der Einfluss der INTERCEPT ${ }^{\mathrm{TM}} \mathrm{Be}$ handlung auf TK lässt sich wie folgt zusammenfassen.

- Die Ergebnisse präklinischer Studien gaben keine Hinweise auf mögliche toxische Wirkungen oder Neo-Antigenbildung der INTERCEPT ${ }^{\mathrm{TM}}$-TK.

- Die INTERCEPT ${ }^{\mathrm{TM}}$ Behandlung von TK führt zu einem moderaten, nicht signifikant von den Kontrollen unterschiedenen Anstieg der Glykolyse.

- In-vitro Teste zeigen eine Beeinträchtigung einzelner Funktionen der Thrombozyten, u. a. eine verringerte Aktivierbarkeit nach Stimulation mit Agonisten und eine verminderte Thrombusbildungsrate.

- Die Bedeutung der Änderungen im mRNA-Profil und im Proteom der Thrombozyten ist noch nicht abschließend geklärt.

- INTERCEPT ${ }^{\mathrm{TM}}$-Thrombozyten sind in der Lage, die hämostatische Funkti- on über eine Lagerdauer von 5 Tagen aufrecht zu erhalten, wie die Ergebnisse von in-vitro Globaltesten zeigen.

- Der herstellungsbedingte Thrombozytenverlust muss durch eine erhöhte Menge im Ausgangspräparat ausgeglichen werden.

\subsection{Das MIRASOL ${ }^{\oplus}$ Pathogen Reduction Technology System}

Das MIRASOL ${ }^{\circledR}$ Pathogen Reduction Technology System (Terumo BCT Europe N.V., Leuven, Belgien) hat eine CE Kennzeichnung für die Anwendung bei Thrombozyten und Plasma [68] erhalten. Es wird gegenwärtig in 18 Ländern für die Inaktivierung von TK angewendet; die Inaktivierung von Plasma mit diesem System ist in 11 Ländern etabliert $[1,4]$.

\subsubsection{Wirkmechanismus und Inaktivierungskapazität}

Das MIRASOL ${ }^{\circledR}$ Pathogen Reduction Technology System (MIRASOL ${ }^{\circ}$ ) benutzt Riboflavin. Riboflavin ist Vitamin B2; es wirkt als Coenzym u.a. in Oxidoreduktasen und hat damit eine wichtige Stoffwechselfunktion. Riboflavin ist ein Derivat des Pteridins mit dem Zuckeralkohol Ribitol (Summenformel $\mathrm{C}_{17} \mathrm{H}_{20} \mathrm{~N}_{4} \mathrm{O}_{6}$ ), der für die Löslichkeit im wässrigen Milieu wichtig ist. Riboflavin wird über die Niere ausgeschieden.

Riboflavin kann sich mit seinem planen, heterozyklischen Teil zwischen Basen der DNA/RNA einlagern. Die Reaktion ist nicht sequenzspezifisch. Licht aktiviert Riboflavin, was durch Elektronentransfer (photochemische Reaktion Typ I) zur Oxidation von Nukleinsäuren, insbesondere Guanin, führt und so die Replikation von Pathogenen verhindert [69]. Riboflavin produziert unter Licht reactive oxygen species (ROS) (photochemische Reaktion Typ II), die hoch reaktiv sind, aber unspezifisch mit unterschiedlichen biologischen Strukturen reagieren. Sie tragen zur Inaktivierung von Mikroorganismen bei. Die für die photochemische Reaktion am meisten wirksamen Frequenzen sind UVB (280-315 $\mathrm{nm})$ und UVA (315$400 \mathrm{~nm})[3,70]$.

Mit verschiedenen Studien wurde die Wirksamkeit von MIRASOL ${ }^{\oplus}$ für die Inaktivierung von Viren, Bakterien und 
Tab. 5 Inaktivierung von Viren durch $\mathrm{MIRASOL}^{\oplus}$. Die Inaktivierungskapazität ist als logarithmischer Faktor der Abnahme der Vermehrungsfähigkeit ( $\log _{10}$ Reduktionsfaktor, LRF) dargestellt

\begin{tabular}{|c|c|c|c|}
\hline MIRASOL ${ }^{\oplus}:$ VIREN & TK & Plasma & Referenzen \\
\hline \multicolumn{4}{|l|}{ VIREN, mit Lipidhülle } \\
\hline HIV (intrazellulär) & 6,46 & $\mathrm{kA}$ & [69] \\
\hline HIV (intrazellulär) & $4,46 \pm 0,39^{b}$ & $\mathrm{kA}$ & {$[72]$} \\
\hline HIV (intrazellulär) & \multicolumn{2}{|c|}{4,5} & {$[70]$} \\
\hline HIV (zellgebunden) & \multicolumn{2}{|c|}{5,9} & \\
\hline HIV (zellgebunden) & $5,93 \pm 0,20^{b}$ & $\mathrm{kA}$ & [72] \\
\hline HIV-1 & $\geq 4,19$ & $\mathrm{kA}$ & {$[32]$} \\
\hline $\mathrm{HCV}$ & $\geq 4,1^{b}$ & $\mathrm{kA}$ & [73] \\
\hline \multirow[t]{2}{*}{ BVDV } & 5,75 & $\mathrm{kA}$ & [69] \\
\hline & 1,83 & $\mathrm{kA}$ & [32] \\
\hline DENV $-1,-2,-3,-4$ & $1,3-1,8$ & $\mathrm{kA}$ & [74] \\
\hline \multirow[t]{2}{*}{ WNV } & $5,19 \pm 0,50^{b}$ & $\mathrm{kA}$ & [72] \\
\hline & \multicolumn{2}{|c|}{$\geq 5,1$} & {$[70]$} \\
\hline BFV & $1,97 \pm 0,31^{c}$ & $\mathrm{kA}$ & {$[75]$} \\
\hline \multirow[t]{2}{*}{ CHIKV } & 2,2 & 2,1 & {$[76]$} \\
\hline & \multicolumn{2}{|c|}{2,1} & [70] \\
\hline MVEV & $1,83 \pm 0,16^{c}$ & $\mathrm{kA}$ & [75] \\
\hline RRV & $2,33 \pm 0,57^{c}$ & $\mathrm{kA}$ & [75] \\
\hline \multirow[t]{2}{*}{ SINV } & \multicolumn{2}{|c|}{3,2} & {$[70]$} \\
\hline & 3,2 & $\mathrm{kA}$ & [73] \\
\hline BoHV 1 & \multicolumn{2}{|c|}{2,1} & [70] \\
\hline MCMV & $\mathrm{kA}$ & $2,1 \pm 0,1^{d}$ & [77] \\
\hline \multirow[t]{4}{*}{ PRV } & 2,5 & $\mathrm{kA}$ & [73] \\
\hline & 6,2 & $>4$ & [69] \\
\hline & 2,73 & $\mathrm{kA}$ & [32] \\
\hline & \multicolumn{2}{|c|}{2,5} & [70] \\
\hline \multirow[t]{2}{*}{ VSV } & $\geq 6,3$ & $\mathrm{kA}$ & [73] \\
\hline & $\geq 6,3$ & & [78] \\
\hline \multirow[t]{2}{*}{ Influenza A Virus } & \multicolumn{2}{|c|}{$\geq 5,0$} & {$[70]$} \\
\hline & $\geq 4,4$ & $\geq 5,5$ & [73] \\
\hline LACV & $\mathrm{kA}$ & $\geq 3,5$ & [73] \\
\hline SFTSV & $\geq 4,1$ & $\mathrm{kA}$ & [79] \\
\hline \multicolumn{4}{|c|}{ VIREN, ohne Lipidhülle } \\
\hline \multirow[t]{4}{*}{ PPV } & $\geq 8,0$ & $\mathrm{kA}$ & [69] \\
\hline & $\geq 5,0$ & $\mathrm{kA}$ & {$[78]$} \\
\hline & $\geq 5,03^{b}$ & $\mathrm{kA}$ & {$[72]$} \\
\hline & 0,28 & $\mathrm{kA}$ & [32] \\
\hline \multirow[t]{2}{*}{ EMCV } & \multicolumn{2}{|c|}{3,2} & {$[70]$} \\
\hline & 3,2 & 3,2 & [73] \\
\hline \multirow[t]{2}{*}{ HEV } & $\geq 2$ (Genotyp 4) & & [71] \\
\hline & $\geq 3$ (Genotyp 3) & & [71] \\
\hline
\end{tabular}

Parasiten gezeigt (s. - Tab. 5, 6 und 7). TK wurden in $100 \%$ Plasma oder in einem Gemisch von Plasma und Additivlösung inaktiviert. In der Tabelle wurden die Spalten für TK und Plasma nicht getrennt, wenn nach Angabe der Autoren die Thrombozyten in Plasma (100 \%) suspendiert waren und die ermittelten Reduktionsfaktoren sowohl für TK als auch für Plasma gelten sollten.

Vergleicht man die von verschiedenen Autoren berichteten $\log _{10}$ Reduktionsfaktoren (LRF), so wurde für HIV eine gute Übereinstimmung gefunden: In allen Experimenten wurde das Virus deutlich oder vollständig inaktiviert. Gute Übereinstimmung in den LRF wurde auch für andere Viren nachgewiesen (WNV, Chikungunya Virus, HAV). Auffällig sind die Unterschiede in der Inaktivierung von BVDV (LRF von 5,8 vs. 1,8), PRV (LRF 6,2 vs. 2,5) und PPV (LRF $\geq 5$ vs. $<1)$. Ursachen für die Unterschiede lassen sich aus den Publikationen nicht vollständig erkennen, könnten aber auf differierende Untersuchungsbedingungen zurückzuführen sein. Kwon und Mitarbeiter verwendeten MIRASOL ${ }^{\circ}$ und führten eine sehr genaue Titration der virushaltigen Proben durch [32]. In der Arbeit von Corbin hingegen sind die genauen Bedingungen der Inaktivierung mit Riboflavin nicht ausreichend gut beschrieben [69]. Da Art und Dauer der Bestrahlung wichtig sind, lässt sich vermuten, dass diese unterschiedlich ausgeführt worden sind. Es ist bemerkenswert, dass größere Unterschiede bei der Inaktivierung von Viren festgestellt wurden, die als Modellvirus für HCV gelten, nämlich die Viren der Familie der Flaviund Togaviren (BVDV, WNV, Sindbis Virus, Chikungunya Virus). Somit können Ergebnisse mit einem Virus nicht ohne weiteres auf ein anderes Virus übertragen werden, auch wenn beide in dieselbe Virusfamilie eingeordnet werden. Für BVDV, Sindbis und Chikungunya Virus ist eine eher geringe Wirksamkeit von MIRASOL ${ }^{\circledR}$ anzunehmen, während WNV offensichtlich gut inaktiviert wurde. Ebenso ist für Herpesviren (BoHV-1 und PRV) eine eher geringe Wirksamkeit (LRF 2,5) zu erwarten, während Influenzaviren und VSV gut inaktiviert wurden $(L R F \geq 5)$. 


\section{Tab. 5 (Fortsetzung)}

\begin{tabular}{|c|c|c|c|}
\hline MIRASOL ${ }^{\circledR}:$ VIREN & TK & Plasma & Referenzen \\
\hline \multirow[t]{3}{*}{ HAV } & 0,62 & $\mathrm{kA}$ & [32] \\
\hline & 1,6 & 2,2 & [73] \\
\hline & \multicolumn{2}{|c|}{1,8} & {$[70]$} \\
\hline
\end{tabular}

$k A$ keine Angaben

${ }^{a} \mathrm{~L} R \mathrm{AF} \geq$ bedeutet, dass im Experiment eine vollständige Inaktivierung erreicht wurde. Die Zahl gibt die Nachweisgrenze an.

${ }^{\mathrm{b}}$ Mittelwert aus 6 Versuchen (MW \pm SD)

cMittelwert aus 4 Versuchen $(\mathrm{MW} \pm \mathrm{SD})$

${ }^{d}$ Inaktivierung von zellfreiem MCMV; Maus $\mathrm{ID}_{50}$ Modell

Tab. 6 Inaktivierung von Bakterien durch MIRASOL ${ }^{\oplus}$. Die Inaktivierungskapazität ist als

logarithmischer Faktor der Abnahme der Vermehrungsfähigkeit $\left(\log _{10}\right.$ Reduktionsfaktor, LRF) dargestellt

\begin{tabular}{lll}
\hline MIRASOL $^{\circledR}$ : BAKTERIEN & TK & Referenzen \\
\hline Bakterien, gram-negativ & $\geq 4,38$ & {$[78]$} \\
$\begin{array}{l}\text { Escherichia coli } \\
\text { Orientia tsutsugamushi }\end{array}$ & $\geq 5,0^{\mathrm{b}}$ & {$[80]$} \\
$\begin{array}{l}\text { Pseudomonas aeruginosa } \\
\text { Serratia marcescens }\end{array}$ & $\geq 4,48$ & {$[78]$} \\
$\begin{array}{l}\text { Bakterien, gram-positiv } \\
\text { Bacillus cereus }\end{array}$ & 4,0 & {$[78]$} \\
$\begin{array}{l}\text { Staphylococcus aureus } \\
\text { Staphylococcus epidermidis }\end{array}$ & 1,$9 ; 2,7$ & {$[78]$} \\
& 3,$56 ; 4,8$ & {$[78]$} \\
\hline a LRF $\geq$ bedeutet, dass im Experiment eine vollständige Inaktivierung erreicht wurde. Die Zahl gibt die Nach- \\
weisgrenze an. & $\geq 4,15$ & {$[78]$} \\
${ }^{b}$ Bestimmt im Mausmodell & $\geq 4,38$ & {$[72]$} \\
\hline
\end{tabular}

In weiteren Untersuchungen wurde die Inaktivierung von Protozoen und Bakterien gezeigt. Die Ergebnisse belegen, dass MIRASOL ${ }^{\oplus}$ Protozoen reduzieren oder sogar vollständig inaktivieren kann. Reduktionsfaktoren für Bakterien, S. epidermidis und E. coli, wurden von Ruane et al. [72] nach Kontamination von TK bestimmt. Die Ergebnisse sind in $\bullet$ Tab. 6 zusammengefasst.

Die Bestimmung von Reduktionsfaktoren erfordert eine hohe Kontamination. Um den Erfolg der PI unter praxisnahen Bedingungen $\mathrm{zu}$ untersuchen, wurde die Inaktivierung verschiedener Bakterienstämme in TK nach niedriger Kontamination im Vergleich zum kulturellen Nachweis untersucht [88]. Es wurden Stämme einbezogen, die für schwere transfusions-assoziierte Infektionen relevant sind: Gram-positive Bakterien (B. cereus, P. acnes, S. aureus, S. epider- midis, $S$. agalactiae, $S$. mitis und $S$. pyogenes) und Gram-negative Bakterien ( $A$. baumannii, E. cloacae, E. coli, K. pneumoniae, S. marcescens, Y. enterocolitica). Die TK wurden nur mit 10-100 CFU/TKEinheit kontaminiert, danach mit MIRASOL $^{\circledR}$ inaktiviert und zum Vergleich nicht inaktiviert. Die Thrombozytenkonzentrate wurden 7 Tage bei $22^{\circ} \mathrm{C}$ gelagert und anschließend auf vermehrungsfähige Erreger geprüft (BacT/Alert ${ }^{\circledast}$, aerobe und anaerobe Kultur über 7 Tage) [70, 89]. Die Inaktivierung von TK mit MIRASOL $^{\circledast}$ war erfolgreich, da nach Lagerung keine Bakterien nachweisbar waren. Nur in einem Fall (P. acnes) war der Versuch nicht aussagefähig, da in der Kontrolle (Testung im BacT/Alert-System nach Kontamination und Lagerung über 7 Tage ohne Inaktivierung) keine vermehrungsfähigen Erreger nachgewiesen wurden. Um ein Anwachsen der Keim- zahl zu vermeiden, sollte die Inaktivierung so früh wie möglich nach Abnahme durchgeführt werden.

Riboflavin und Licht inaktivieren nicht nur Pathogene, sondern auch Leukozyten. MIRASOL $^{\bullet}$ ist deshalb eine Alternative zur Gammabestrahlung, die bei TK für bestimmte Patientengruppen eingesetzt wird, um eine TA-GvHD zu vermeiden. Außerdem wird die Antigenpräsentation vermindert und die Ausschüttung von leukozytären Zytokinen während der Lagerung der TK gehemmt [90-96].

Der Wirkmechanismus und die Wirksamkeit der Pathogeninaktivierung in TK durch MIRASOL ${ }^{\circledast}$ lassen sich in folgenden Punkten zusammenzufassen:

- Die Inaktivierung von Pathogenen erfolgt durch Einlagerung von Riboflavin in die Nukleinsäure. Die nachfolgende Bestrahlung mit UV-Licht aktiviert Riboflavin und bewirkt durch Elektronentransfer die Oxidation von Nukleinsäuren, was zu DNAbzw. RNA-Strangbrüchen führen kann. Um seine Wirkung zu entfalten, muss Riboflavin mit Nukleinsäuren in Kontakt kommen, also Zellwände, Kapside etc. durchdringen können.

- Riboflavin und seine Oxidationsprodukte sind nicht toxisch, so dass die TK nach Bestrahlung sofort einsetzbar sind.

- Verschiedene Studien zeigten die Wirksamkeit von MIRASOL ${ }^{\circledR}$ für die Inaktivierung von Viren; eine gute Wirksamkeit wurde gegenüber Retroviren (HIV), Rhabdoviren (VSV) und Hepaciviren (HCV) nachgewiesen, während für Flaviviren (BVDV, WNV) und Parvovirus (PPV) von verschiedenen Autoren unterschiedliche LRF berichtet wurden und Herpesviren (BoHV-1, PRV, MCMV), Togaviren (Sindbis Virus, Ross River Virus, Chikungunya Virus u. a.) und Picornaviren (HAV) nur ungenügend inaktiviert wurden.

- Eine gute Wirksamkeit wurde für Bakterien und einige Protozoen gezeigt.

- MIRASOL ${ }^{\oplus}$ ist wirksam für die Inaktivierung von Leukozyten: Proliferation und Proteinsynthese werden unterbunden; die Methode wird als Alternative zur Gammabestrahlung 
Tab. 7 Inaktivierung von Protozoen durch MIRASOL ${ }^{\oplus}$. Die Inaktivierungskapazität ist als logarithmischer Faktor der Abnahme der Vermehrungsfähigkeit ( $\log _{10}$ Reduktionsfaktor, LRF) dargestellt

\begin{tabular}{llll}
\hline MIRASOL ${ }^{\circledR}$ : PROTOZOEN & TK & Vollblut & Referenzen \\
\hline Babesia microti & $\geq 4-5^{\mathrm{b}}$ & $\mathrm{kA}$ & {$[81]$} \\
& $\mathrm{kA}$ & $\geq 5^{\mathrm{c}}$ & {$[82]$} \\
Leishmania donovani & $\mathrm{kA}$ & $2.3 \pm 0.12^{\mathrm{d}}$ & {$[83]$} \\
& $\geq 4,0$ & $\mathrm{kA}$ & {$[70]$} \\
Plasmodium falciparum & $\mathrm{kA}$ & $\approx 6,4$ & {$[84]$}
\end{tabular}

gesehen. Außerdem wird die Antigenpräsentation vermindert und die Ausschüttung von Zytokinen während der Lagerung gehemmt.

\subsubsection{Unerwünschte Effekte der Pathogeninaktivierung mit MIRASOL ${ }^{\circledR}$}

Unerwünschte Effekte der PI von TK mit MIRASOL ${ }^{\circledR}$ betreffen mögliche toxische Effekte der Riboflavin-Photoderivate, die Bildung von Neo-Antigenen, Veränderungen von in-vitro Stoffwechsel- und Funktionsparametern und Einflüsse auf die mRNA bzw. mi-RNA sowie das Proteom der Thrombozyten.

Riboflavin ist nicht toxisch [97]. Die wichtigsten Abbauprodukte des Riboflavins als Ergebnis des photochemischen Prozesses sind Lumichrom und Lumiflavin. Der Riboflavinabbau ist zeitabhängig [98]. Umfangreiche toxikologische Untersuchungen sind unternommen worden, um die Sicherheit der mit MIRASOL ${ }^{\oplus}$ behandelten Blutprodukte nachzuweisen (Übersicht in $[69,70]$ ). Die Abbauprodukte von Riboflavin treten auch als natürliche Stoffwechselprodukte auf. Experimentell wurde gezeigt, dass Lumichrom und Riboflavin nicht mutagen sind und auch keine Chromosomenaberrationen durch Bruch eines Chromosoms induzieren. Daher müssen überschüssiges Riboflavin oder Abbauprodukte nicht entfernt werden.

Untersuchungen im Serum von $44 \mathrm{~Pa}$ tienten vor und 28 Tage nach Transfusion von MIRASOL-TK ergaben keine Hinweise auf eine Neo-Antigen-Bildung (Capture $\mathrm{P}^{\circledast}$ Technology) oder auf eine erhöhte Rate an Auto- und Allo-Antikörpern (PAKAUTO und PAK12 Test) [99].

Die MIRASOL ${ }^{\circledR}$ Behandlung bewirkt eine spontane Thrombozytenaktivierung und damit verbunden einen signifikanten Anstieg der anaeroben Glykolyse für die Energiegewinnung, gemessen als erhöhter Glukoseverbrauch, gestiegene Laktatproduktion und $\mathrm{pH}$-Erniedrigung [100105]. Ausdruck der Aktivierung sind u.a. die erhöhte $p$-Selektin (CD62p)-Expression, Annexin V-Bindung sowie eine verstärkte Freisetzung von thrombozytären Zytokinen wie TGF $\beta$ und PF4 und die Aktivierung des Fibrinogenrezeptors GPIIb/IIIa. Das Ausmaß der Beeinträchtigung von Funktionsparametern wie die hypotone Schockresistenz (HSR) und die mit unterschiedlichen Agonisten stimulierte Aggregation wird quantitativ unterschiedlich berichtet $[58,101-104$, 106-110]. Abhängig von den Versuchsbedingungen wurde sowohl über eine erhöhte Spontanaggregation und verminderte Thrombozytenadhäsion an Kollagen oder Subendothel $[111,112]$ als auch über eine erhöhte Thrombusbildung an Kollagen [113] berichtet. Unter Scherkraft zeigte sich eine verminderte Thrombusbildungsrate über die gesamte Lagerdauer [51].

Insgesamt bewerten die meisten der Autoren das Ausmaß der Änderung von Metabolismus und Funktion der Thrombozyten durch MIRASOL $^{\circledR}$ als vereinbar mit Vorgaben zur Qualität von TK.

Die Auswirkungen der Inaktivierung mit MIRASOL ${ }^{\circledR}$ auf die ThrombozytenmRNA wurden unterschiedlich beschrieben. Während anti-apoptotische mRNA unverändert erhalten blieb [61], wurden signifikante Verminderungen der mRNA für die untersuchten adhäsiven Proteine gefunden [114]. Dabei wurden Unterschiede in der Stabilität der untersuchten mRNAs festgestellt. Das Ausmaß der Schädigung stieg mit der Größe der mRNA; miRNAs blieben unbeeinflusst. Die Autoren konnten vor allem für die Glykoprotein-mRNAs zeigen, dass die Halbwertszeit der restlichen, durch PI nicht geschädigten mRNA verlängert wurde, und vermuten einen Transkriptions-unabhängigen Schutzmechanismus. Auffallend war ein im Vergleich zu kernhaltigen Zellen insgesamt wesentlich langsamer verlaufender mRNA-Abbau. Da die Proteinkonzentration nicht nur von der mRNA-Menge, sondern vor allem von Translations- und Degradationsrate bestimmt wird, ist der Einfluss der beobachteten mRNA-Verminderung auf Proteintranslation und post-translationale Modifikationen noch offen. Weitere Studien sind erforderlich, um einen $\mathrm{Zu}$ sammenhang zwischen dem MIRASOL ${ }^{\circledR}$ Effekt auf die mRNA-Stabilität und dem beobachteten Funktionsverlust durch PI zu zeigen.

Riboflavin produziert unter Licht reactive oxygen species (ROS) (photochemische Reaktion Typ II), die hoch reaktiv sind, unspezifisch mit unterschiedlichen biologischen Strukturen reagieren und zur Inaktivierung von Mikroorganismen beitragen. Sie können aber auch Reaktio- 
nen mit Zellen und Plasmaproteinen eingehen und so zu den beobachteten Einbußen an Wirksamkeit und Haltbarkeit der PI-TK führen [17, 115, 116]. Dennoch finden sich nach einer PI mit MIRASOL ${ }^{\circ}$ nur geringe Veränderungen am Gesamtproteom [67]. Veränderungen wurden gefunden bei Proteinen, die für die Zytoskelett-Regulierung, also für Adhäsion und "shape change“ der Thrombozyten, eine Rolle spielen [117].

Der Herstellungsprozess führte nur zu einem minimalen Verlust an Thrombozyten [103].

Von allen untersuchten in-vitro Parametern zeigten nur Laktatproduktion und pH bzw. Glukoseverbrauch eine Korrelation zur Wiederfindung und Überlebensrate der Thrombozyten in Probanden [118, 119].

Der Einfluss der MIRASOL ${ }^{\circledR}$ Behandlung auf TK lässt sich wie folgt zusammenfassen:

- Riboflavin und dessen Abbauprodukte sind nicht toxisch und müssen daher nach der MIRASOL ${ }^{\oplus}$ Behandlung nicht entfernt werden.

- In präklinischen Studien gab es keine Anzeichen einer Neo-Antigen-Bildung oder Unverträglichkeit.

- Die MIRASOL ${ }^{\oplus}$ Behandlung von TK führt zu einem signifikant von den Kontrollen unterschiedenen Anstieg der Glykolyse.

- In-vitro Teste zeigen eine spontane Thrombozytenaktivierung, einhergehend u. a. mit Zytokinfreisetzung, und eine Beeinträchtigung einzelner Funktionen der Thrombozyten wie einer Verringerung der Agonisteninduzierten Aggregationsfähigkeit, einer erhöhten Annexin V-Bindung und einer verminderten Thrombusbildungsrate.

- Untersuchungen zu mRNA-Profil und Proteom von MIRASOL ${ }^{\circledR}$-TK zeigten vor allem eine Verminderung von mRNA und Proteinen, die eine Rolle in der Adhäsion spielen.

- Die MIRASOL ${ }^{\circledR}$ Behandlung führt nicht zu einem relevanten Verlust an Thrombozyten im TK.

\subsection{THERAFLEX UV-Platelets System}

Das THERAFLEX UV-Platelets System des Pharmaunternehmens Macopharma hat 2009 die CE-Kennzeichnung für die Inaktivierung von Viren, Bakterien, Protozoen und Spender-Leukozyten in ATK und PTK bekommen. Bisher ist dieses System in der klinischen Erprobung und noch nicht in der routinemäßigen Anwendung $[1,120]$.

\subsubsection{Wirkmechanismus und Inaktivierungskapazität}

THERAFLEX basiert auf der Anwendung von kurzwelligem ultraviolettem Licht (UVC) mit einer Wellenlänge von $254 \mathrm{~nm}$ (200 bis $280 \mathrm{~nm}$ ). Über eine UVC vermittelte kovalente Vernetzung von Nukleotiden kommt es zu einem Verlust der Replikationsfähigkeit von Pathogenen und kernhaltigen Zellen. Dieses Resultat wird vorrangig durch die Bildung von Cyclobutan-Pyrimidin- und Pyrimidin-Pyrimidin-Dimeren erreicht, die die Elongation der Nukleinsäure-Transkripte blockieren. Bevorzugt ist die Reaktion zwischen benachbarten Pyrimidinen. Übersteigt die Zahl der Treffer auf die DNA/RNA von Pathogenen oder Zellen die Reparaturkapazität, dann ist die Replikation unterbunden bzw. die Zellen sterben ab [121, 122].

Für die Wirksamkeit ist unbedingt eine gleichmäßige Bestrahlung aller Bestandteile im Beutel erforderlich. Sie wird dadurch erreicht, dass die Beutel zur optimalen Durchmischung während des Bestrahlungsvorganges gleichmäßig mit definierter Amplitude und Geschwindigkeit bewegt werden und dabei die Schichtdicke zeitlich und räumlich variiert.

Die Inaktivierung von Pathogenen durch Reaktion von UVC mit Nukleinsäuren kann einhergehen mit der Zerstörung oder Schädigung von Zellen, Proteinen oder anderen aktiven Substanzen. Aufgrund der unterschiedlichen Absorptionsmaxima für Nukleinsäuren $(254 \mathrm{~nm})$ und Proteinen $(280 \mathrm{~nm})$ sollte dieser Effekt für Proteine von untergeordneter Bedeutung sein. Da vorrangig Nukleinsäuren degradiert werden, kommt es zu einer Inaktivierung von Bakterien und Viren sowie Leukozyten, während die Funktionalität der Throm- bozyten und der Gerinnungsfaktoren erhalten bleibt. Da für die inaktivierende Wirkung von UVC auf Pathogene keine photoaktiven Substanzen benötigt werden, sind Nebenwirkungen durch toxische Photoprodukte primär nicht $\mathrm{zu}$ erwarten, und die Anwendung der Präparate kann direkt nach der Bestrahlung erfolgen.

Während der Entwicklung des UVCVerfahrens wurde die Inaktivierung von Viren, Bakterien und Protozoen in Abhängigkeit von der UVC-Dosis untersucht. Dabei zeigte sich mit steigender UVC-Dosis eine Zunahme der Inaktivierungseffizienz [123]. Das THERAFLEX Verfahren ist gegenwärtig für TK in Additivlösung mit einer UV-Dosis von 0,2 $\mathrm{J} / \mathrm{cm}^{2}$ ausgelegt [121]. Diese Spezifikation wurde auch in der präklinischen Entwicklung des THERAFLEX UV-Platelets Verfahrens verwendet $[124,125]$.

In den $\bullet$ Tab. 8, 9 und 10 sind die Inaktivierungskapazitäten mit dieser Spezifikation zusammengefasst.

Auffällig sind die geringe Wirksamkeit von UV zur Inaktivierung von HIV und die relativ gute Inaktivierung von nichtumhüllten Viren wie HAV und PPV [127, 132]. Andere umhüllte Viren wie Dengue Virus (DENV) 1-4, ChikungunyaVirus (CHIKV), Ross River Virus (RRV) und Zikavirus (ZIKV) wurden ebenfalls gut inaktiviert $[128,131]$.

THERAFLEX ist für die Inaktivierung eines breiten Spektrums von Bakterien [121] einschließlich der Stämme des kürzlich etablierten Referenzpanels der WHO [133] geeignet (• Tab. 9).

Die Wirkung von THERAFLEX auf Protozoen wurde mit Trypanosoma cru$z i$, Leishmania infantum, Plasmodium falciparum und Babesia divergens untersucht [135-137]. In der Inaktivierungsstudie mit Babesien wurde in 12 von 15 kontaminierten TK eine vollständige Inaktivierung erreicht $\left(\mathrm{LRF} \geq 6,0 \log _{10}\right)$ und in den restlichen 3 TK eine Inaktivierung bis zur Nachweisgrenze (LRF 5,0 $\log _{10}$ ). Auch für die anderen Protozoen (Trypanosoma cruzi, Leishmania infantum und Plasmodium falciparum) wurden mit dem THERAFLEX-Verfahren hohe Inaktivierungsraten erzielt. Damit ist die Wirksamkeit des Systems auch für Protozoen gezeigt. - Tab. 10 fasst die Inakti- 
Tab. 8 Inaktivierung von Viren durch das THERAFLEX UV-Platelets System. Die Inaktivierungskapazität ist als logarithmischer Faktor der Abnahme der Vermehrungsfähigkeit $\left(\log _{10}\right.$ Reduktionsfaktor, LRF) a dargestellt

\begin{tabular}{lll}
\hline THERAFLEX: VIREN & TK & Referenzen \\
\hline VIREN, mit Lipidhülle & & \\
BVDV & 3,1 & {$[126,127]$} \\
CHIKV & 6,3 & {$[128]$} \\
DENV-1 & $\geq 5,3$ & {$[128]$} \\
DENV-2, DENV-3, DENV-4 & $\geq 4,4$ & {$[128]$} \\
HCV & $\geq 4,99$ & {$[126]$} \\
HIV-1 & 1,0 & {$[129]$} \\
Influenza $\left(\mathrm{H}_{3} \mathrm{~N}_{2}\right)$ & $\geq 5,3$ & {$[130]$} \\
RRV & $\geq 5,1$ & {$[128]$} \\
SHV-1 & 3,6 & {$[127,129]$} \\
SINV & $\geq 5,3$ & {$[129]$} \\
VSV & $\geq 6,3$ & {$[129]$} \\
WNV & $3,5-4$ & {$[129]$} \\
ZIKV & $\geq 5,0$ & {$[131]$} \\
VIREN, ohne Lipidhülle & & \\
EMCV & 3,8 & {$[127]$} \\
HAV & $\geq 4,1$ & {$[132]$} \\
PPV & 5,0 & {$[129]$} \\
a LRF $\geq$ bedeutet, dass im Experiment eine vollständige Inaktivierung erreicht wurde. Die Zahl gibt die Nach- \\
weisgrenze an. & & \\
\hline
\end{tabular}

vierungsdaten von THERAFLEX für Protozoen zusammen.

Da UVC mit Nukleinsäuren reagiert, kann durch die Bestrahlung nicht nur die Replikation von Pathogenen, sondern auch die Proliferation von restlichen im Präparat verbliebenen Leukozyten verhindert werden. Pohler und andere untersuchten in vitro die Proliferation von T-Zellen im Vergleich zu mit Gammastrahlen (25 Gy) behandelten Zellen und kamen zu dem Ergebnis, dass THERAFLEX die Gammabestrahlung nicht nur ersetzen kann, sondern weitere Vorteile hat, indem die UVC-Bestrahlung die Antigenpräsentation vermindert und die Ausschüttung von leukozytären $\mathrm{Zy}$ tokinen während der Lagerung der TK hemmt. Darüber hinaus konnte die Verhinderung einer GvHD auch in einem humanisierten Mausmodell gezeigt werden [138].

Der Wirkmechanismus und die Wirksamkeit der Pathogeninaktivierung in TK durch MIRASOL ${ }^{\circledR}$ lassen sich nach jetzigem Kenntnisstand in folgenden Punkten zusammenfassen:
- THERAFLEX basiert auf der Applikation von kurzwelligem, ultraviolettem Licht mit einer Wellenlänge von $254 \mathrm{~nm}$ (200 bis $280 \mathrm{~nm}$ ). Über eine UVC-vermittelte kovalente Vernetzung von Nukleotiden kommt es zu einem Verlust der Replikationsfähigkeit von Pathogenen und kernhaltigen Zellen.

- Da bei dem THERAFLEX-Verfahren keine zusätzlichen Pathogen-inaktivierenden Substanzen zugesetzt werden, wird von keinem erhöhten Risiko unerwünschter toxischer Reaktionen bei den TK-Empfängern ausgegangen.

- Die gegenwärtige Datenbasis spricht für eine breite Wirksamkeit des THERAFLEX-Systems für Viren, Bakterien und Protozoen.

- Auffällig sind die geringe Wirksamkeit gegenüber HIV und die gute Wirksamkeit gegenüber kleinen, nicht-umhüllten Viren, wie HAV und PPV. Auch für andere transfusionsrelevante Viren, wie HCV, HCMV, Influenza und die soge- nannten emerging viruses DENV 1-4, CHIKV, RRV und ZIKV werden hohe LRF berichtet.

- Hohe LRF mit WHO ReferenzBakterienstämmen bestätigen, dass THERAFLEX auch für die Inaktivierung von Bakterien wirksam ist.

- Untersuchungen zu Trypanosoma cruzi, Leishmania infantum, Plasmodium falciparum und Babesia divergens zeigen, dass auch Protozoen inaktiviert werden.

- THERAFLEX ist wirksam für die Inaktivierung von Leukozyten: Proliferation und Proteinsynthese werden unterbunden; die Methode wird als Alternative zur Gammabestrahlung gesehen. Außerdem wird die Antigenpräsentation vermindert und die Ausschüttung von Zytokinen während der Lagerung gehemmt.

\subsubsection{Unerwünschte Effekte der Pathogeninaktivierung mit THERAFLEX}

Unerwünschte Effekte der PI von TK mit THERAFLEX betreffen mögliche Unverträglichkeiten durch die UV-bestrahlten TK, die Bildung von Neo-Antigenen, Veränderungen von in-vitro Stoffwechselund Funktionsparametern und Einflüsse auf das RNA-Profil sowie das Proteom der Thrombozyten.

In einem autologen Hundemodell mit wiederholten Gaben autologer UVC-TK wurden weder lokale noch systemische Unverträglichkeiten beobachtet. Ebenso wenig konnten Antikörper gegen Plasma- oder Thrombozyten-Neo-Antigene nachgewiesen werden [139]. In einer Probandenstudie mit steigender Dosis an autologen UVC-TK wurden zudem keine unerwünschten Reaktionen beobachtet, und es konnten keine Antikörper gegen Neo-Antigene gefunden werden [124].

Der Einfluss der UVC-Behandlung auf die in-vitro Funktionalität der Thrombozyten scheint gering zu sein. Beschrieben sind eine erhöhte Glykolyserate sowie ein moderater, aber signifikanter Anstieg der Annexin V-Bindung und der GP IIb/IIIa-Expression, während die Werte für $p$-Selektin oder Zytokinfreisetzung (TGF $\beta$, RANTES) sich nicht von den Kontrollen unterschieden; ebenso 
Tab. 9 Inaktivierung von Bakterien durch das THERAFLEX UV-Platelets System. Die Inaktivierungskapazität ist als logarithmischer Faktor der Abnahme der Vermehrungsfähigkeit $\left(\log _{10}\right.$ Reduktionsfaktor, LRF) a dargestellt

\begin{tabular}{lll} 
THERAFLEX: BAKTERIEN & TK & Referenzen \\
\hline Bakterien, gram-negativ & & \\
Enterobacter cloacae & $6,3 \pm 0,6$ & {$[134]$} \\
Escherichia coli & $7,3 \pm 0,4$ & {$[127]$} \\
Klebsiella pneumoniae & $5,9 \pm 0,7$ & {$[127]$} \\
Morganella morganii & $7,5 \pm 0,3$ & {$[134]$} \\
Proteus mirabilis & $7,0 \pm 0,6$ & {$[134]$} \\
Pseudomonas aeruginosa & $\geq 4,92$ & {$[121]$} \\
Pseudomonas fluorescens & $7,1 \pm 0,4$ & {$[134]$} \\
Serratia marcescens & $5,8 \pm 0,2$ & {$[134]$} \\
Bakterien, gram-positiv & & \\
Bacillus cereus & $4,3 \pm 0,81$ & {$[121]$} \\
Clostridium perfringens & $\geq 4,73$ & {$[121]$} \\
Propionibacterium acnes & $4,53 \pm 1,13$ & {$[121]$} \\
Staphylococcus aureus & $6,6 \pm 0,4$ & {$[134]$} \\
Staphylococcus epidermidis & $4,6 \pm 0,5$ & {$[127]$} \\
Streptococcus bovis & $7,0 \pm 0,3$ & {$[134]$} \\
Streptococcus dysgalactiae & $3,5 \pm 0,3$ & {$[134]$} \\
Streptococcus pyogenes & $4,4 \pm 0,8$ & {$[134]$} \\
Streptococcus pyogenes & $4,1 \pm 0,9$ & {$[127]$} \\
\hline a LRF: $\geq$ bedeutet, dass im Experiment eine vollständige Inaktivierung erreicht wurde. Die Zahl gibt die Nach- \\
weisgrenze an. & & \\
\hline
\end{tabular}

Tab. 10 Inaktivierung von Protozoen durch das THERAFLEX UV-Platelets System. Die Inaktivierungskapazität ist als logarithmischer Faktor der Abnahme der Vermehrungsfähigkeit ( $\log _{10}$ Reduktionsfaktor, LRF) ${ }^{\text {a dargestellt }}$

\begin{tabular}{|c|c|c|}
\hline THERAFLEX: PROTOZOEN & TK & Referenzen \\
\hline Trypanosoma cruzi & $\geq 2,8-\geq 4,2$ & [135] \\
\hline Leishmania infantum & $\geq 1,4^{b}$ & [135] \\
\hline Plasmodium falciparum & 8,$0 ; 4-5^{c}$ & [136] \\
\hline Babesia divergens & $5,0-\geq 6,0$ & [137] \\
\hline \multicolumn{3}{|c|}{$\begin{array}{l}\text { a LRF } \geq \text { bedeutet, dass im Experiment eine vollständige Inaktivierung erreicht wurde. Die Zahl gibt die Nach- } \\
\text { weisgrenze an. } \\
\text { bAssay mit nur kleinem dynamischen Bereich und hoher Nachweisgrenze } \\
\text { 'quantitativer PCR-Assay }\end{array}$} \\
\hline
\end{tabular}

ist die Aktivierbarkeit der Thrombozyten nicht signifikant beeinträchtigt [140, 141]. Untersuchungen in der Mikroflusskammer zeigten eine verminderte Kinetik der Gerinnselbildung an Kollagen ab Lagertag 5 [142].

Es wurden nur geringere Änderungen im Proteom der THERAFLEX-behandelten Thrombozyten gefunden. Es sind vor allem Proteine betroffen, die an der Agonisten-induzierten Veränderung der Zell- morphologie (shape change) und der Adhäsion beteiligt sind [123].

Der Einfluss der THERAFLEX-Behandlung auf TK lässt sich wie folgt zusammenfassen:

- Präklinische Untersuchungen gaben keine Hinweise auf Unverträglichkeiten oder Neo-Antigen-Bildung mit THERAFLEX-TK.

- Es kommt in vitro zu einem signifikanten Anstieg der Glykolyse.
- Außer einem moderaten, aber signifikanten Anstieg weniger Aktivierungsmarker wie die Annexin V-Bindung wurde kaum eine Beeinträchtigung der in-vitro Funktion von THERAFLEX-TK beschrieben. Auffällig erschien die verminderte Gerinnselbildungsrate am Ende der Lagerdauer.

- UVC-Behandlung hat einen relativ geringen Einfluss auf das Proteom der Thrombozyten.

\section{Vergleichende Betrachtung der Inaktivierungsmethoden}

\subsection{Parameter und Handhabung der PI-Systeme}

Alle hier beschriebenen PI-Systeme sind CE-zertifizierte Medizinprodukte, die damit in der EU marktfähig sind. Die Handhabung ist in $\bullet$ Tab. 11 zusammengefasst. Alle Prozess-Schritte erfolgen im funktionell geschlossenen System.

Der bei INTERCEPT ${ }^{\mathrm{TM}}$ herstellungsbedingte Verlust an Thrombozyten sollte durch eine entsprechende Erhöhung der initialen Thrombozytenzahl, wie für $\mathrm{Zu}$ lassungen in Deutschland vorgeschrieben, ausgeglichen werden.

\subsection{Wirksamkeit der PI-Systeme gegenüber Pathogenen}

\subsubsection{Viren}

Alle Verfahren zeigen grundsätzlich eine gute Inaktivierung von Viren, haben aber auch Limitierungen, die zu beachten sind. Kwon und Mitarbeiter verglichen z. B. die Inaktivierung durch MIRASOL ${ }^{\oplus}$ und INTERCEPT ${ }^{\mathrm{TM}}$. Sie fanden eine bessere Inaktivierung der umhüllten Viren BVDV und PRV durch INTERCEPT ${ }^{\mathrm{TM}}$ (BVDV $1,8 \log _{10}$ vs. $\geq 6,0 \log _{10}$; PRV 2,7 $\log _{10}$ vs. $\geq 5,2 \log _{10}$ ), während HIV durch INTERCEPT $^{\mathrm{TM}}$ und MIRASOL ${ }^{\circledR}$ gleich gut inaktiviert wurde $\left(\geq 4,19 \log _{10}\right.$ vs. $\geq 4,23 \log _{10}$ ) [32]. Vergleichbar niedrige Inaktivierung wurde in beiden Systemen für die nicht-umhüllten Viren berichtet (HAV 0,62 $\log _{10}$ vs. 0,76 $\log _{10}$ und für PPV 0,27 $\log _{10}$ vs. 0,38 $\log _{10}$ ). Jedoch konnte durch die Behandlung mit MIRA$\mathrm{SOL}^{\circledR}$ eine Reduktion von HEV Genotyp 3 und 4 eine Reduktion von $\geq 2-\geq 3 \log _{10}$ erreicht werden [71]. Von anderen $\mathrm{Au}$ - 


\begin{tabular}{|c|c|c|c|}
\hline & INTERCEPT TM & MIRASOL ${ }^{\circledast}$ & THERAFLEX \\
\hline CE -Einstufung & CE Klasse III & CE Klasse IIb & CE Klasse IIb \\
\hline $\begin{array}{l}\text { Zulassungsstatus von PI-TK in } \\
\text { Deutschland, } \\
\text { Stand } 2016\end{array}$ & Zugelassen seit 2007 & in klinischer Prüfung & in klinischer Prüfung \\
\hline $\begin{array}{l}\text { Vorbereitung } \\
\text { (Wechsel des Beutelsystems) }\end{array}$ & $\begin{array}{l}\text { Überführung in Bestrahlungsbeutel, } \\
\text { Zugabe von Amotosalen }\end{array}$ & $\begin{array}{l}\text { Überführung in Bestrahlungsbeutel, } \\
\text { Zugabe von Riboflavin }\end{array}$ & $\begin{array}{l}\text { Überführung in Bestrahlungs- } \\
\text { beutel }\end{array}$ \\
\hline $\begin{array}{l}\text { Inaktivierungs- } \\
\text { prozess }\end{array}$ & $\begin{array}{l}\text { 4-6 Min UVA-Bestrahlung in Bestrah- } \\
\text { lungsgerät, ausgelegt für die Dosis von } \\
3 \mathrm{~J} / \mathrm{cm}^{2}\end{array}$ & $\begin{array}{l}\text { 5-10 Min UVB-Bestrahlung in } \\
\text { Bestrahlungsgerät, ausgelegt für die } \\
\text { Dosis von } 6,2 \mathrm{~J} / \mathrm{ml}\end{array}$ & $\begin{array}{l}1 \text { Min UVC-Bestrahlung in Be- } \\
\text { strahlungsgerät, ausgelegt für die } \\
\text { Dosis von } 0,2 \mathrm{~J} / \mathrm{cm}^{2}\end{array}$ \\
\hline $\begin{array}{l}\text { Entfernung des PI-Agens } \\
\text { (Wechsel des Beutelsystems) }\end{array}$ & $\begin{array}{l}\text { 4-16 h Inkubation zur Entfernung der } \\
\text { Amotosalen-Restprodukte im „Com- } \\
\text { pound Adsorption Device“ (CAD- Beutel) }\end{array}$ & entfällt & entfällt \\
\hline $\begin{array}{l}\text { Überführung in Lagerbeutel } \\
\text { (Wechsel des Beutelsystems) }\end{array}$ & $\begin{array}{l}\text { 1:1 Überführung in einen Lagerbeutel } \\
\text { bzw. Aufteilung in 2-3 Lagerbeutel }\end{array}$ & & \\
\hline
\end{tabular}

Tab. 12 Wiederfindung und Überleben von 5 Tage alten TK nach autologer Transfusion in gesunden Probanden

\begin{tabular}{|c|c|c|c|c|c|c|}
\hline & \multicolumn{2}{|l|}{$\begin{array}{l}\text { INTERCEPT }^{\mathrm{TM}} \\
{[145]}\end{array}$} & \multicolumn{2}{|l|}{$\begin{array}{l}\text { MIRASOL }^{\oplus} \\
{[118]}\end{array}$} & \multicolumn{2}{|l|}{$\begin{array}{l}\text { THERAFLEX } \\
{[140]}\end{array}$} \\
\hline & Wiederfindung (\%) & Überleben (Tage) & Wiederfindung (\%) & Überleben (Tage) & Wiederfindung (\%) & Überleben (Tage) \\
\hline TK ohne PI & $50,3 \pm 7,7$ & $6,0 \pm 1,2$ & $66,5 \pm 13,4$ & $5,9 \pm 1,1$ & $37,6 \pm 6,5$ & $7,3 \pm 0,9$ \\
\hline PI-TK & $42,5 \pm 8,7$ & $4,8 \pm 1,3$ & $50,0 \pm 18,9$ & $4,3 \pm 1,1$ & $28,0 \pm 8,2$ & $5,2 \pm 1,3$ \\
\hline Differenz & $16 \%$ & $20 \%$ & $25 \%$ & $27 \%$ & $26 \%$ & $29 \%$ \\
\hline$p$-Wert & $<0,01$ & $<0,01$ & $<0,05$ & $<0,05$ & $=0,026$ & $=0,004$ \\
\hline
\end{tabular}

toren wurden mit MIRASOL ${ }^{\oplus}$ für Flaviviren (BVDV, WNV) und Parvovirus (PPV) unterschiedliche LRF berichtet. Für THERAFLEX ist die geringe Wirksamkeit gegenüber HIV auffällig. Es hat jedoch eine gute Wirksamkeit gegenüber kleinen, nicht-umhüllten Viren, wie HAV und PPV. Durch weitere Untersuchungen und insbesondere vergleichende Testungen könnte das Wirkungsspektrum der drei Inaktivierungsmethoden noch besser definiert werden.

\subsubsection{Bakterien}

Aus den Untersuchungen zur Inaktivierung einer breiten Palette von transfusionsrelevanten Bakterienstämmen wurde geschlossen, dass alle drei Verfahren das Risiko bakterieller Kontamination von TK reduzieren können. Die Inaktivierung sollte so früh wie möglich angewendet werden, um eine Biofilmbildung [143, 144] oder eine Vermehrung kontaminierender Bakterien auf eine hohe Keimzahl zu verhindern. In beiden Fällen könnte sonst die Wirksamkeit der PI-Systeme nicht ausreichend sein.

\subsubsection{Protozoen}

Durch die drei PI-Verfahren werden auch Protozoen inaktiviert, einschließlich T. cruzi, P. falciparum, L. infantum und B. microti. Die höchsten LRF wurden nach Inaktivierung mit INTERCEPT ${ }^{\mathrm{TM}}$ beschrieben.

\subsubsection{Prionen}

Aufgrund ihres Wirkmechanismus sind alle drei PI-Systeme unwirksam zur Inaktivierung von Prionen.

\subsection{Wirksamkeit der PI-Systeme zur Verhinderung einer GvHD}

Alle drei PI-Systeme inhibieren die Leukozytenproliferation und können die Gammabestrahlung ersetzen.

\subsection{Vergleich der Ergebnisse von klinischen Studien bzw. klinischen Erfahrungen mit INTERCEPT ${ }^{\mathrm{TM}}$ und MIRASOL ${ }^{\circledR}$ Sowie THERAFLEX}

\subsubsection{Wiederfindungsrate von Thrombozyten in gesunden Probanden}

Die Transfusion markierter autologer PIbehandelter TK zeigte eine signifikante Verringerung sowohl der Wiederfindungs- als auch der Überlebensrate verglichen mit unbehandelten TK bei allen drei Verfahren [118, 140, 145-147].

\subsubsection{Klinische Studien}

Auch im klinischen Einsatz kommt es nach der Gabe von pathogeninaktivierten TK im Vergleich zu unbehandelten TK im Mittel zu einem geringeren Anstieg der beim Patienten gemessenen Thrombozytenzahl. Als Messgröße wird hierzu der korrigierte Anstieg der Thrombozytenzahl 1 Stunde nach der TK-Gabe verwendet (CCI-1 h=1-hour corrected count increment). 
Tab. 13 Darstellung von möglichen Risiken bei der Gabe von Pathogen-reduzierten Thrombozytenkonzentraten hergestellt mit INTERCEPT ${ }^{\mathrm{TM}}$, MIRASOL ${ }^{\oplus}$ oder THERAFLEX

\begin{tabular}{ll} 
Mögliche Risiken & Amotosalen/UVA INTERCEPT \\
\hline & SPRINT Phase III Studie \\
& ( $n=318$ vs. 327) \\
ergänzende Hämovigilanzdaten & \\
& {$[151]$} \\
& Grad 2 Blutungen \\
& $58,5 \%$ (186 Pat.) in PI-TK Gruppe und 57,5 \% (188 Pat.) in \\
Schwerwiegende & der Kontrollgruppe \\
Blutungsereignisse & kein signifikanter Unterschied ( $p<0,1 ;$ Non inferiority \\
& Test) \\
& Grad 3 oder 4 Blutungen \\
& $4,1 \%(13$ Pat.) und 6,1 \% (20 Pat.) in der Kontrollgruppe \\
& $(p<0,1)-$
\end{tabular}

Allergische Reaktionen SPRINT Studie: Häufigkeit akuter Transfusionsreaktionen in PI-TK Gruppe $16 \%$ (51 Pat.) und in der Kontrollgruppe $19,3 \%$ (63 Pat.) $(p=0,2)$

Post Marketing Hemovigilance Program:

Nicht-schwerwiegende allergische Reaktionen (z.B.

Urtikaria, Schüttelfrost, Temperaturerhöhung) häufigste Nebenwirkung

Immunologische

Refraktärität

SPRINT Studie; $6 \%$ der initial klinisch refraktären Patienten in der PI-TK Gruppe und $9 \%$ der refraktären Patienten in der Kontroll-Gruppe entwickelten eine anhaltende Refraktärität. Bei dem Nachweis von thrombozytären Alloantikörpern bzw. lymphozytären Antikörpern wurde eine immunologische Refraktärität angenommen. Es fand sich kein signifikanter Unterschied für das Auftreten von thrombozytären wie für lymphozytäre Antikörpern $(p=0,6$ bzw. $p=1,0)$

Respiratorische Komplikationen

Initiale Auswertung der SPRINT Studie: Hinweise auf das vermehrte Auftreten respiratorischer Komplikationen in der PI-TK Gruppe (unspezifische Pneumonitis, pleuritischer Thoraxschmerz, ARDS)

Bei genauer Klassifizierung der Symptomatik (MedRA) und einer Analyse der Studien-Patienten mit vergleichbar schweren Grunderkrankungen: es wurde kein signifikanter Unterschied zwischen der PI-TK- und Kontroll-Gruppe gefunden $[156,157]$

Eine Auswertung des Post Marketing Hemovigilance Program ergab ebenfalls keine erhöhte Melderate von respiratorischen Komplikationen bei der Gabe von PI-TK

Phototoxizität bei Neugeborenen

Präklinische Daten: Gefahr einer Phototoxizität bei einer erhöhten Amotosalen-Exposition (1000fach höhere Konzentration als im TK nach Amotosalen-Behandlung) Zurzeit liegen keine Sicherheitsdaten aus klinischen Studien für Kinder unter 6 Jahren vor Hämovigilanz-System der Firma: Keine Meldungen von Phototoxizität bei Neugeborenen dokumentiert Der Wellenlängenbereich bei der Phototherapie eines Neugeborenen-lkterus liegt bei $455 \mathrm{~nm}$ und der beim PI-Verfahren bei 320 bis $400 \mathrm{~nm}$

Transfusions-bedingte Infektionen

In der SPRINT Studie wurden keine transfusionsbedingten viralen oder bakteriellen Infektionen nach PI-TK-Gabe bestätigt [156]

In dem Hämovigilanz System der Firma Cerus ist bisher keine produktassoziierte Infektion dokumentiert worden. Die Hämovigilanz-Systeme in der Schweiz und in Frankreich haben bisher keine Pathogenübertragung durch TK nach Amotosalen/UVA-Behandlung registriert

Riboflavin/UVB MIRASOL ${ }^{\circledR}$

Multicenter-Studie

( $n=60$ vs. 58 )

[155]

Phase I-Studie

Grad 2-4 Blutungen

21,4 \% (12 Pat.) in der PI-TK Gruppe und $13,0 \%$ (7 Pat.) in der Kontrollgruppe,

kein signifikanter Unterschied

$(p<0,1$; Non inferiority Test)

Häufigkeit schwerwiegender allergischer Reaktionen

Kein Patient in der PI-TK-Gruppe und $3,3 \%$ (2 Pat.) in der Kontrollgruppe

3,6 \% (2 Pat.) der PI-TK Gruppe und $7,45 \%$ (4 Pat.) entwickelten HLA Antikörper ( $p=0,43$; Fisher's exact test). Insgesamt 4,5\% (5 von 110 Patienten entwickelten eine klinische Refraktärität, 3 Patienten der PI-TK Gruppe und 2 Patienten der Kontrollgruppe $(p=1,0$; Fisher's exact test)

In der MIRASOL ${ }^{\circledR}$ Studie trat bei keinem Patienten eine respiratorische Komplikation auf

In der MIRASOL ${ }^{\circledR}$ Studie wurden keine Neugeborenen bzw. Kinder unter 6 Jahren behandelt

In der MIRASOL ${ }^{\circledR}$ Studie waren die Infektionsraten in der MIRASOL ${ }^{\oplus}$ - und Kontroll-Gruppe vergleichbar und wurden zudem als nicht TK-assoziiert klassifiziert
Keiner der 11 Probanden entwickelte eine Transfusionsreaktion (z. B. Allergische Reaktion, Blutdruckabfall, Fieber, Thrombo-embolische Komplikationen etc.)

Bei keinem der Probanden wurden thrombozytäre Antikörper und keine erhöhten IgE-Werte in einem Zeitraum von 9 Wochen nachgewiesen

Es liegen keine Untersuchungsergebnisse vor

Es werden keine photoaktiven Substanzen eingesetzt

Es liegen keine Untersuchungsergebnisse vor 
Von klinisch größerer Bedeutung ist jedoch die Anzahl der (schwerwiegenden) Blutungen bzw. der Transfusionsbedarf. Hierzu wurden in klinischen Studien (s. - Tab. 13) und in der Anwendung [148] keine Unterschiede gefunden.

In systematischen Reviews für INTER$\mathrm{CEPT}^{\mathrm{TM}}$ und MIRASOL ${ }^{\circledR}$ wurden schwerwiegende Blutungen und Refraktärität als Endpunkte bewertet: Der Cochrane-Report [149] verglich 10 Studien mit insgesamt 1422 Patienten, in denen PI-behandelte TK mit nicht behandelten verglichen wurden. Neun von diesen betrafen INTERCEPT $^{\text {TM }}$-TK. Die untersuchten Studien wiesen eine Heterogenität hinsichtlich verschiedener Aspekte wie EndpunktDefinition, Transfusionsprotokolle Dauer der Nachbeobachtung auf. Die Meta-Analyse von fünf Studien, die als Endpunkt „Blutung“ definiert hatten, zeigte signifikant mehr Blutungen über einen längeren Betrachtungszeitraum mit einer Auswertungsmethode (fixed effect model). Dieses Ergebnis zeigte sich nicht mehr in der Metaanalyse mit einem anderen Modell (random effects model). Die Patienten benötigten im Mittel $7 \%$ mehr TK-Transfusionen, und es fand sich ein signifikant höherer Anteil an Refraktärität. Die Autoren dieses Reviews fanden zusammenfassend keine Evidenz für Unterschiede in Mortalität, klinisch relevanter Blutung, schwerer Blutung oder unerwünschten Ereignissen zwischen PI-TK und unbehandelten TK. Für eine Reihe von Laborparametern zeigten sich unbehandelte TK überlegen gegenüber PI-behandelten. Aufgrund der Variabilität und der Größe der einzelnen Studien halten die Autoren die Daten jedoch nicht für ausreichend, um die Schlussfolgerung zu ziehen, dass PI-behandelte TK gleichwertig sind. Den Vergleich erschweren qualitative (bis 5 Tage oder bis 7 Tage gelagert) und quantitative Unterschiede (Thrombozytenzahl/Einheit) der verwendeten TK.

Bei einer Aktualisierung des Reviews konnten zwei weitere abgeschlossene Studien mit zusammen 559 Teilnehmern einbezogen werden; drei weitere werden aktuell durchgeführt, diese wurden aber noch nicht in die Analyse einbezogen [150]. Der erweiterte Review bestätigte im Wesentlichen die Ergebnisse der ersten Analyse: Es fand sich weiterhin kei- ne oder wahrscheinlich keine Evidenz für Unterschiede in Mortalität, klinisch relevanter Blutung, schwerer Blutung oder unerwünschten Ereignissen zwischen PITK und unbehandelten TK. Hinsichtlich des Endpunkts ,jede Blutung“ fanden die Autoren erneut einen geringfügigen Unterschied abhängig vom Analysemodell zugunsten nicht-behandelter TK. Die Autoren fanden auch mit Einschluss der neueren Studien, dass die Anwendung von PIbehandelten TK signifikant häufiger zu Refraktärität und auch zur Entwicklung von anti-thrombozytären Antikörpern führte. Allerdings dominierte in dieser Sub-Analyse eine Studie [151] mit knapp $58 \%$ der Daten. Die Autoren halten es für essentiell, dass unerwünschte Effekte bei der Anwendung von PI-behandelten TK sehr genau protokolliert werden. Es gibt derzeit keine Studien, welche INTER$\mathrm{CEPT}^{\mathrm{TM}}$-TK und MIRASOL ${ }^{\circledR}$-TK miteinander vergleichen. Unterschiede in Subgruppenanalysen weisen nach Auffassung der Autoren des aktualisierten CochraneReviews auf einen Vorteil von INTER$\mathrm{CEPT}^{\mathrm{TM}}$ hin bezüglich Gesamtmortalität und Transfusionsintervall.

Sämtliche eingeschlossenen Studien betrafen ganz überwiegend (>97 \%) hämatologisch-onkologische Patienten, so dass hinsichtlich der untersuchten Parameter keine Aussage zur Wirksamkeit und zu potenziellen unerwünschten Reaktionen bei anderen Patientengruppen getroffen werden kann.

In einer der prospektiven, randomisierten open-label Studie wurden TK in Plasma, TK in Additivlösung und INTERCEPT $^{\mathrm{TM}}$-TK mit dem primären Studienziel verglichen, Unterschiede im 1-h-CCI zu finden. Die Autoren fanden verringerte 1-Stunden und 24-Stunden CCI-Werte und mehr Blutungen (insbesondere auch fünf Grad 3 Blutungen) im INTERCEPT $^{\mathrm{TM}}$-Arm gegenüber einer bei Plasma-TK und 0 bei TK in Additivlösung [152]. Der Unterschied in der Blutungshäufigkeit ist u.a. wegen des Studiendesigns und der zu geringen Anzahl der in die Studie eingeschlossenen Patienten nicht signifikant [153]. Eine 2018 publizierte, prospektive, randomisierte noninferiority Studie an hämatologischen, thrombozytopenischen Patienten hat ebenfalls die Wirksamkeit von INTER-
CEPT $^{\mathrm{TM}}$-TK mit TK in Plasma bzw. TK in Additivlösung verglichen. Unterschiede wurden nur für Grad-2-Blutungen zwischen PI-TK (47,9 \%) und Plasma-TK (43,5 \%), nicht aber zu TK in Additivlösung $(45,3 \%)$ gefunden. Die 3 Studienarme unterschieden sich nicht hinsichtlich Grad-3- und -4-Blutungen [154].

Es liegen noch keine Ergebnisse aus klinischen Phase-III-Studien mit THERAFLEX-TK vor.

Eine Zusammenfassung der möglichen Risiken bei der Gabe von Pathogenreduzierten Thrombozytenkonzentraten hergestellt mit INTERCEPT ${ }^{\mathrm{TM}}$, MIRA$\mathrm{SOL}^{\circledR}$ oder THERAFLEX findet sich in - Tab. 13.

\subsubsection{Erfahrungen aus Routineanwendungen}

Die Wirksamkeit von INTERCEPT ${ }^{\mathrm{TM}}$ TK bei einem routinemäßigen Einsatz lässt sich auf der Grundlage der Schweizer Hämovigilanzdaten relativ gut darstellen. Seit der Einführung der Pathogeninaktivierung für Thrombozytenkonzentrate im Jahr 2011 wurden demnach der Schweizer Überwachungsbehörde keine transfusionsassoziierten bakteriellen Infektionen gemeldet. Des Weiteren kam es zu einer Abnahme von nicht schwerwiegenden allergischen Transfusionsreaktionen, was auf die geänderte Zusammensetzung der Lagerlösung zurückgeführt wurde. Eine gleichzeitige landesweite Zunahme des Verbrauchs an TK oder EK als Hinweise einer eventuell eingeschränkten hämostatischen Wirkung der INTERCEPT ${ }^{\mathrm{TM}}$-TK wurde nicht beobachtet [148]. Gleiches wurde von einem großen österreichischen Klinikum berichtet [158]. Aufgrund der bisher vorliegenden Sicherheitsdaten kann für alle drei PI-Systeme ein verminderter Thrombozytenanstieg gegenüber einer entsprechenden unbehandelten Kontrollgruppe festgestellt werden. Ein erhöhter EK- oder TK-Verbrauch oder eine erhöhte Blutungsneigung lassen sich mit den veröffentlichten klinischen Studien nicht belegen.

\subsubsection{Mögliche unerwartete Reaktionen}

Unerwartete Reaktionen wie allergische Reaktionen, immunologische Refraktärität und Phototoxizität bei Neugeborenen 
wurden diskutiert, aber Studien- wie auch die Hämovigilanzdaten geben bislang keinen Hinweis auf ein nachweisbares Risiko [159]. Die Auswertung der Schweizer INTERCEPT $^{\mathrm{TM}}$-Hämovigilanzdaten (Spontanmeldungen) für die Jahre 2011/2012 ergab keine Zunahme der Melderate von schwerwiegenden respiratorischen Komplikationen [160].

Eine mögliche Toxizität, Kanzerogenität und Genotoxizität bei dem Empfänger von Pathogen-inaktivierten TK wurde wiederholt thematisiert und im Rahmen von pharmakologisch-toxikologischen Studien untersucht.

Die Ergebnisse der präklinischen pharmakokinetischen und toxikologischen Studien sowie der vorliegenden klinischen Studien (s. - Tab. 13) geben jedoch keinen Hinweis auf das Vorliegen von möglichen Risiken für Amotosalenbzw. Riboflavin-behandelte Thrombozytenkonzentrate.

Für alle drei Systeme sollten weitere potenzielle Risiken in Betracht gezogen und ggf. untersucht werden. Daten aus zukünftigen Studien bzw. Meldungen aus der Routineanwendung sollten auf bisher nicht bekannte bzw. nicht ausreichend beschriebene Risiken geprüft werden.

\section{Bewertung}

Aktuell haben drei PI-Systeme für die Herstellung von Thrombozytenkonzentraten eine CE-Zertifizierung: Das INTERCEPT $^{\mathrm{TM}}$ Blood System, das MIRASOL ${ }^{\bullet}$ System und das THERAFLEX-System. Die einzelnen Verfahren weisen Unterschiede im Wirkungsspektrum auf. Es gibt Limitierungen hinsichtlich der Wirksamkeit gegenüber bestimmten transfusionsmedizinisch relevanten Pathogenen. Da alle drei Systeme auf Inaktivierung von Nukleinsäuren basieren, inaktivieren sie keine Prionen. Die Daten zur Reproduzierbarkeit der Reduktionsfaktoren und zur Breite des Wirkungsspektrums bedürfen der Ergänzung.

Alle in-vitro Studien zeigen in Abhängigkeit von Methodik und Versuchsbedingungen in unterschiedlichem Ausmaß und Ausprägung eine Beeinträchtigung von Metabolismus und Funktionalität der mit einem PI-Verfahren behandelten Thrombozyten. Die Frage nach der klini- schen Relevanz dieser Ergebnisse bleibt offen.

Für alle drei Systeme gibt es bislang weder aus den klinischen Studien noch aus Hämovigilanzdaten Hinweise auf Probleme bezüglich Toxizität, Sensibilisierung oder Neo-Antigenität. Hinsichtlich seltener oder später auftretender unerwünschter Reaktionen nach der Anwendung von TK, die mit einem PI-Verfahren behandelt wurden, besteht Bedarf an gezielter Datenerhebung im Sinne einer intensivierten Hämovigilanz nach Markteinführung.

Alle drei PI-Systeme hemmen die Leukozyten-Proliferation und verhindern damit wirksam eine GvHD.

Systeme zur Pathogeninaktivierung sind grundsätzlich geeignet, das Infektionsrisiko durch Thrombozytenkonzentrate zu verringern. In Deutschland ist jedoch das Risiko einer transfusionsassoziierten Infektion mit TK derzeit durch die Spenderauswahl, die Testung der Spenden auf die wichtigsten transfusionsrelevanten Erreger und durch weitere Maßnahmen wie Leukozytendepletion, Abtrennung des initialen Blutvolumens von der Blutspende (Predonation Sampling), Optimierung der Herstellungsverfahren (Kontrolle von SCD-Schweißnähten) und Beschränkung der Lagerungsdauer sehr gering. So sind in den Jahren 2012-2015 auf 2.022.453 transfundierte TK 10 bakterielle (1 tödlich), keine HIV- oder HCV-, $1 \mathrm{HBV}$ - und 4 HEV-Infektionen gemeldet worden.

Auch bei Einsatz von PI-Verfahren sind Übertragungen von Pathogenen aufgrund von Limitierungen im Wirkungsspektrum und in der Kapazität der PI-Methoden nicht auszuschließen.

Treten allerdings neue Erreger auf oder ändert sich die epidemiologische Situation, kann die Einführung von PI-TK einen erheblichen Sicherheitsgewinn erbringen, sofern die Erreger durch das Verfahren inaktiviert werden können. Der Sicherheitsgewinn tritt insbesondere dann ein, wenn andere präventive Maßnahmen, wie Spenderselektion und -testung, nicht praktikabel sind oder nicht den Erfordernissen entsprechend schnell eingeführt werden können und nur dadurch die Versorgung gewährleistet werden kann. Diese Voraussetzungen treffen aktuell nicht zu. Dennoch sollten bereits jetzt Strategien für die
Implementierung und Finanzierung von Pathogen-inaktivierten Blutkomponenten erarbeitet werden.

Die Bewertung, ob eine geänderte epidemiologische Situation vorliegt, welche die Einführung von PI-Maßnahmen erforderlich macht, sollte situationsbezogen, aber mindestens alle zwei Jahre durchgeführt werden.

Für den Arbeitskreis Blut

\section{Dr. R. Offergeld}

Vorsitzende

Dieses Papier wurde fertiggestellt am 18.01.2018 und vom Arbeitskreis Blut am 18.04.2018 verabschiedet. Es wurde erarbeitet von den Mitgliedern der Untergruppe „Bewertung Blut-assoziierter Krankheitserreger" des Arbeitskreises Blut: Prof. Dr. Markus Funk, Dr. Margarethe Heiden, Dr. Hannelore Willkommen, Prof. Dr. Martin Aepfelbacher, Dr. Ursula Bauerfeind, Prof. Dr. Isabelle Bekeredjian-Ding, PD Dr. Johannes Blümel, Prof. Dr. Reinhard Burger, Dr. Manfred Doll, Dr. Albrecht Gröner, Prof. Dr. Lutz Gürtler, Prof. Dr. Martin Hildebrandt, Prof. Dr. Dr. Bernd Jansen, Dr. Ruth Offergeld, Prof. Dr. Georg Pauli, Dr. Uwe Schlenkrich, Dr. Volkmar Schottstedt, Prof. Dr. Rainer Seitz, PD Dr. Dorothea Stahl, Dr. Johanna Strobel.

\section{Literatur}

1. AABB (2015) Listing of countries in which pathogen reduction technology systems and products are in use. https://www.aabb.org/tm/eid/Documents/prt-systems-in-use-country-listing.pdf. Zugegriffen: 18. Mai 2018

2. Salunkhe V, van der Meer PF, de Korte D, Seghatchian J, Gutiérrez L (2015) Development of blood transfusion product pathogen reduction treatments: A review of methods, current applications and demands. Transfus Apher Sci 52:19-34

3. Marks DC, Faddy HM, Johnson L (2014) Pathogen reduction technologies. ISBT Sci Ser 9:44-50

4. Custer B (2013) Update on pathogen reduction technology. ISBT Sci Ser 8:80-84

5. Schlenke P (2014) Pathogen inactivation technologies for cellular blood components: an update. Transfus Med Hemother 41:309-325

6. REGULATION (EU) $2017 / 745$ OF THE EUROPEAN PARLIAMENT AND OF THE COUNCIL of 5 April 2017 on medical devices, amending Directive 2001/83/EC, Regulation (EC) No 178/2002 and Regulation (EC) No 1223/2009 and repealing Council Directives 90/385/EEC and 93/42/EEC 
http://data.europa.eu/eli/reg/2017/745/oj

Zugegriffen: 18.05. 2018

7. Funk MB, Lohmann A, Spranger R (2015) Hämovigilanz-Bericht des Paul-Ehrlich-Instituts 2013/14. http://www.pei.de/haemovigilanzbericht. Zugegriffen: 18. Mai 2018

8. Funk MB, Heiden M (2017) Hämovigilanz-Bericht des Paul-Ehrlich-Instituts 2015: Auswertung der Meldungen von schwerwiegenden Reaktionen und Zwischenfällen nach § 63i AMG. http:// www.pei.de/haemovigilanzbericht. Zugegriffen: 18. Mai 2018

9. Walther-Wenke $\mathrm{G}$, Wirsing von König $\mathrm{CH}$, Däubener W et al (2011) Monitoring bacterial contamination of blood components in Germany: effect of contamination reduction measures. Vox Sang 100:359-366

10. Irsch J, Lin L (2011) Pathogen inactivation of platelet and plasma blood components for transfusion using the INTERCEPT ${ }^{\text {TM }}$ Blood System. Transfus Med Hemother 38:19-31

11. CERUS Pressemitteilung vom 16.12.2014. http:// www.cerus.com/Investors/Press-Releases/ Press-Release-Details/2014/FDA-ApprovesINTERCEPT-Blood-System-for-Plasma/default. aspx. Zugegriffen: 18. Mai 2018

12. CERUS Pressemitteilung vom 18.12.2014. http:// www.cerus.com/Investors/Press-Releases/ Press-Release-Details/2014/FDA-ApprovesINTERCEPT-Blood-System-for-Platelets/default. aspx. Zugegriffen: 18. Mai 2018

13. Liu W, Cimino GD, Corash L, Lin L (2011) The extent of amotosalen photodegradation during photochemical treatment of platelet components correlates with the level of pathogen inactivation. Transfusion 51:52-61

14. Hanson CV (1992) Photochemical inactivation of viruses with psoralens: an overview. Blood Cells 18:7-25

15. Wollowitz S (2001) Fundamentals of the psoralen-based Helinx technology for inactivation of infectious pathogens and leukocytes in platelets and plasma. Semin Hematol 38:4-11

16. Kanne D, Straub K, Hearst JE, Rapoport H (1982) Isolation and characterization of pyrimidinepsoralen-pyrimidine photodiadducts from DNA. J Am Chem Soc 104:6754-6764

17. Prudent M, Sonego G, Abonnenc M, Tissot JD, Lion N (2014) LC-MS/MS Analysis and Comparison of Oxidative Damages on Peptides Induced by Pathogen Reduction Technologies for Platelets. J Am Soc Mass Spectrom 25:651-661

18. Sonego $G$, Abonnenc M, Tissot JD, Prudent $M$, Lion N (2017) Redox Proteomics and Platelet Activation: Understanding the Redox Proteome to Improve Platelet Quality for Transfusion. Int J Mol Sci 18:387-408

19. Lin L, Londe H, Janda JM, Hanson CV, Corash $L$ (1994) Photochemical inactivation of pathogenic bacteria in human platelet concentrates. Blood 83:2698-2706

20. Lin L, Cook ND, Wiesehahn GP et al (1997) Photochemical inactivation of viruses and bacteria in platelet concentrates by use of a novel psoralen and long-wavelength ultraviolet light. Transfusion 37:423-435

21. Lin $L$ (2001) Inactivation of cytomegalovirus in platelet concentrates using Helinx technology. Semin Hematol 38:27-33

22. Lin L, Dikeman R, Molini B et al (2004) Photochemical treatment of platelet concentrates with amotosalen and long-wavelength ultraviolet light inactivates a broad spectrum of pathogenic bacteria. Transfusion 44:1496-1504

23. Lin L, Hanson CV, Alter HJ et al (2005) Inactivation of viruses in platelet concentrates by photochemical treatment with amotosalen and long-wavelength ultraviolet light. Transfusion 45:580-590

24. Eastman RT, Barrett LK, Dupuis K, Buckner FS, Van Voorhis WC (2005) Leishmania inactivation in human pheresis platelets by a psoralen (amotosalen $\mathrm{HCl}$ ) and long-wavelength ultraviolet irradiation. Transfusion 45:1459-1463

25. Jauvin V, Alfonso RD, Guillemain B, Dupuis $\mathrm{K}$, Fleury HJ (2005) In vitro photochemical inactivation of cell-associated human T-cell leukemia virus Type I and II in human platelet concentrates and plasma by use of amotosalen. Transfusion 45:1151-1159

26. Pinna D, Sampson-Johannes A, Clementi M et al (2005) Amotosalen photochemical inactivation of severe acute respiratory syndrome coronavirus in human platelet concentrates. Transfus Med 15:269-276

27. Gallian P, Vignoli C, Dombey AM et al (2006) Inactivation of a European strain of West Nile virus in single-donor platelet concentrate using the INTERCEPT blood system. Vox Sang 91:345-347

28. Roback JD, Conlan M, Drew WL, Ljungman P, Nichols WG, Preiksaitis JK (2006) The role of photochemical treatment with amotosalen and UV-A light in the prevention of transfusiontransmitted cytomegalovirus infections. Transfus Med Rev 20:45-56

29. Brecher ME, Hay S, Corash L, Hsu J, Lin L (2007) Evaluation of bacterial inactivation in prestorage pooled, leukoreduced, whole blood-derived platelet concentrates suspended in plasma prepared with photochemical treatment. Transfusion 47:1896-1901

30. Nussbaumer W, Allerstorfer D, Grabmer C et al (2007) Prevention of transfusion of platelet components contaminated with low levels of bacteria: a comparison of bacteria culture and pathogen inactivation methods. Transfusion 47:1125-1133

31. Grellier P, Benach J, Labaied M et al (2008) Photochemical inactivation with amotosalen and long-wavelength ultraviolet light of Plasmodium and Babesia in platelet and plasma components. Transfusion 48:1676-1684

32. Kwon SY, Kim IS, Bae JE et al (2014) Pathogen inactivation efficacy of MIRASOL PRT System and INTERCEPT Blood System for non-leucoreduced platelet-rich plasma-derived platelets suspended in plasma. Vox Sang 107:254-260

33. Musso D, Richard V, Broult J, Cao-Lormeau VM (2014) Inactivation of dengue virus in plasma with amotosalen and ultraviolet $\mathrm{A}$ illumination. Transfusion 54:2924-2930

34. Aubry M, Richard V, Green J, Broult J, Musso D (2016) Inactivation of Zika virus in plasma with amotosalen und ultraviolet $\mathrm{A}$ illumination. Transfusion 56:33-40

35. CERUS (2016) INTERCEPTTM Plasma Technical Data Sheet. http://interceptbloodsystem.com/ sites/default/files/resources/technical data sheet_-_plasma_-_english.pdf. Zugegriffen: 18. Mai 2018

36. CERUS (2017) INTERCEPT ${ }^{T M}$ Platelets Technical Data Sheet. http://interceptbloodsystem.com/ sites/default/files/resources/prd-tds_00121_ v9.0_secure_0.pdf. Zugegriffen: 18. Mai 2018
37. Hauser L, Roque-Alfonso AM, Beylouné $A$ et al (2014) Hepatitis E transmission by transfusion of INTERCEPT blood system-treated plasma. Blood 123:796-797

38. Juhl D, Baylis $S A$, Blümel J, Görg $S$, Hennig H (2014) Seroprevalence and incidence of hepatitis Evirus infection in German blood donors. Transfusion 54:49-56

39. Panning M, Umhau M, Emmerich F, Wedemeyer $\mathrm{H}$, Pischke S (2015) Diskussion zu dem Beitrag Hepatitis E in Deutschland-eine unterschätzte Infektionskrankheit. Dtsch Arztebl 112:220

40. Baylis SA, Corman VM, Ong E, Linnen JM, Nübling CM, Blümel J (2016) Hepatitis E viral loads in plasma pools for fractionation. Transfusion 56:2532-2537

41. Domanovic D, Tedder R, Blümel J et al (2017) Hepatitis $E$ and blood donation safety in selected European countries: a shift to screening? EuroSurveille 22:30514

42. Schmidt M, Hourfar MK, Sireis W et al (2015) Evaluation of the effectiveness of a pathogen inactivation technology against clinically relevant transfusion-transmitted bacterial strains. Transfusion 55:2104-2112

43. Störmer M, Arroyo A, Brachert J et al (2012) Establishment of the first international repository for transfusion-relevant bacteria reference strains: ISBT working party transfusion-transmitted infectious diseases (WP-TTID), subgroup on bacteria. Vox Sang 102:22-31

44. Benjamin RJ, Wagner SJ (2015) Bacterial pathogen reduction requires validation under conditions of intended use. Transfusion 55:2060-2063

45. Grass JA, Hei DJ, Metchette K et al (1998) Inactivation of leukocytes in platelet concentrates by photochemical treatment with psoralen plus UVA. Blood 91:2180-2188

46. Grass JA, Wafa T, Reames A et al (1999) Prevention of transfusion-associated graft-versus-host disease by photochemical treatment. Blood 93:3140-3147

47. Tice RR, Gatehouse D, Kirkland D, Speit G (2007) The pathogen reduction treatment of platelets with S-59 HCl (Amotosalen) plus ultraviolet A light: Genotoxicity profile and hazard assessment. Mut Res 630:50-68

48. Lin L, Conlan MG, Tessman J, Cimino G, Porter $S$ (2005) Amotosalen interactions with platelet and plasma components: absence of neoantigen formation after photochemical treatment. Transfusion 45:1610-1620

49. Van Rhenen DJ, Vermeij J, Mayaudon V, Hind C, Lin L, Corash L (2000) Functional characteristics of S-59 photochemically treated platelet concentrates derived from buffy coats. Vox Sang 79:206-214

50. Jansen $\mathrm{GA}$, van Vlieth HH, Vermeij $\mathrm{H}$ et al (2004) Functional characteristics of photochemically treated platelets. Transfusion 44:313-319

51. Van Aelst B, Feys HB, Devloo R, Vanhoorelbeke $\mathrm{K}$, Vandekerckhove P, Compernolle V (2015) Riboflavin and amotosalen photochemical treatments of platelet concentrates reduce thrombus formation kinetics in vitro. Vox Sang 108:328-339

52. Apelseth TO, Bruserud O, Wentzel-Larsen T, Bakken AM, Bjorsvik S, Hervig T (2007) In vitro evaluation of metabolic changes and residual platelet responsiveness in photochemical treated and gamma-irradiated single-donor platelet concentrates during long-term storage. Transfusion 47:653-665 
53. Johnson L, Loh YS, Kwok M, Marks DS (2013) In vitro assessment of buffy-coat derived platelet components suspended in SSP+ treated with the INTERCEPT Blood system. Transfus Med 23:121-129

54. Janetzko K, Lin L, Eichler $\mathrm{H}$, Mayaudon V, Flament J, Klüter H (2004) Implementation of the INTERCEPT Blood System for Platelets into routine blood bank manufacturing procedures: evaluation of apheresis platelets. Vox Sang 86:239-245

55. Picker SM, Speer R, Gathof BS (2004) Functional characteristics of buffy-coat PLTs photochemically treated with amotosalen- $\mathrm{HCl}$ for pathogen inactivation. Transfusion 44:320-329

56. Sandgren P, Diedrich B (2015) Pathogen inactivation of double-dose buffy-coat platelet concentrates photochemically treated with amotosalen and UVA light: preservation of in vitro function. Vox Sang 108:340-349

57. Lozano M, Galan A, Mazzara R, Corash L, Escolar $G$ (2007) Leukoreduced buffy coat-derived platelet concentrates photochemically treated with amotosalen $\mathrm{HCl}$ and ultraviolet $\mathrm{A}$ light stored up to 7 days: assessment of hemostatic function under flow conditions. Transfusion 47:666-671

58. Picker SM, Schneider V, Gathof BS (2009) Platelet function assessed by shear-induced deposition of split triple-dose apheresis concentrates treated with pathogen reduction technologies. Transfusion 49:1224-1232

59. Hechler B, Ohlmann P, Chafey P et al (2013) Preserved functional and biochemical characteristics of platelet components prepared with amotosalen and ultraviolet $A$ for pathogen inactivation. Transfusion 53:1187-1200

60. Tynngard N, Johansson BM, Lindahl TL, Berlin G, Hansson M (2008) Effects of INTERCEPT pathogen inactivation on platelet function as analysed by free oscillation rheometry. Transfus Apher Sci 38:85-88

61. Osman A, Hitzler WE, Meyer CU et al (2015) Effects of pathogen reduction systems on platelet microRNAs, mRNAs, activation, and function. Platelets 26:154-163

62. Bakkour S, Chafets DM, Wen L et al (2016) Assessment of nucleic acid modification induced by amotosalen and ultraviolet A light treatment of platelets and plasma using real-time polymerase chain reaction amplification of variable length fragments of mitochondrial DNA. Transfusion 56:410-420

63. Laffont B, Corduan A, Plé H et al (2013) Activated platelets can deliver mRNA regulatory Ago2-microRNA complexes to endothelial cells via microparticles. Blood 122:253-261

64. Semple JW (2013) Platelets deliver small packages of genetic function. Blood 122:155-156

65. Osman A, Hitzler WE, Ameur A, Provost P (2015) Differential Expression Analysis by RNA-Seq Reveals Perturbations in the Platelet mRNA Transcriptome Triggered by Pathogen Reduction Systems. Plos One 10:e133070

66. Prudent M, Crettaz D, Delobel J, Tissot JD, Lion N (2012) Proteomic analysis of Intercept-treated platelets. J Proteomics 76:316-328

67. Prudent M, D'Alessandro A, Cazenave JP et a (2014) Proteome changes in platelets after pathogen inactivation--an interlaboratory consensus. Transfus Med Rev 28:72-83

68. Terumo BCT MIRASOL ${ }^{\circledR}$ Pathogen Reduction Technology System, 05.12.2014. https://www. terumobct.com/mirasol. Zugegriffen: 22. Mai 2018

69. Corbin F (2002) Pathogen inactivation of blood components: current status and introduction of an approach using riboflavin as a photosensitizer. Int J Hematol 76(Suppl 2):253-257

70. Marschner S, Goodrich R (2011) Pathogen reduction technology treatment of platelets, plasma and whole blood using riboflavin and UV light. Transfus Med Hemother 38:8-18

71. Owada T, Kaneko M, Matsumoto C et al (2014) Establishment of culture systems for genotypes 3 and 4 hepatitis E virus (HEV) obtained from human blood and application of HEV inactivation using a pathogen reduction technology system. Transfusion 54:2820-2827

72. Ruane PH, Edrich R, Gampp D, Keil SD, Leonard RL, Goodrich RP (2004) Photochemical inactivation of selected viruses and bacteria in platelet concentrates using riboflavin and light. Transfusion 44:877-885

73. Keil SD, Bengrine A, Bowen R et al (2015) Inactivation of viruses in platelet and plasma products using a riboflavin-and-UV-based photochemical treatment. Transfusion 55:1736-1744

74. Faddy HM, Fryk JJ, Watterson D et al (2016) Riboflavin and ultraviolet light: impact on dengue virus infectivity. Vox Sang 111:235-241

75. Faddy HM, Prow NA, Fryk JJ et al (2015) The effect of riboflavin and ultraviolet light on the infectivity of arboviruses. Transfusion 55:824-831

76. Vanlandingham DL, Keil SD, Horne KM, Pyles R, Goodrich RP, Higgs S (2013) Photochemical inactivation of chikungunya virus in plasma and platelets using the MIRASOL pathogen reduction technology system. Transfusion 53:284-290

77. Keil SD, Saakadze N, Bowen R et al (2015) Riboflavin and ultraviolet light for pathogen reduction of murine cytomegalovirus in blood products. Transfusion 55:858-863

78. Goodrich RP, Edrich RA, Li J, Seghatchian J (2006) The MIRASOL ${ }^{\text {TM }}$ PRT system for pathogen reduction of platelets and plasma: an overview of current status and future trends. Transfus Apher Sci 35:5-17

79. Shinohara N, Matsumoto C, Chatani M et al (2015) Efficacy of the MIRASOL pathogen reduction technology system against severe fever with thrombocytopenia syndrome virus (SFTSV). Vox Sang 109:417-419

80. Rentas F, Harman R, Gomez C et al (2007) Inactivation of Orientia tsutsugamushi in red blood cells, plasma, and platelets with riboflavin and light, as demonstrated in an animal model. Transfusion 47:240-247

81. Tonnetti L, Proctor MC, Reddy HL, Goodrich RP, Leiby DA (2010) Evaluation of the MIRASOL pathogen reduction technology system against Babesia microti in apheresis platelets and plasma. Transfusion 50:1019-1027

82. Tonnetti L, Thorp AM, Reddy HL, Keil SD, Goodrich RP, Leiby DA (2013) Riboflavin and ultraviolet light reduce the infectivity of Babesia microti in whole blood. Transfusion 53:860-867

83. Tonnetti L, Thorp AM, Reddy HL et al (2015) Reduction of Leishmania donovani infectivity in whole blood using riboflavin and ultraviolet light. Transfusion 55:326-329

84. El Chaar M, Atwal S, Freimanis GL, Dinko B, Sutherland CJ, Allain JP (2013) Inactivation of Plasmodium falciparum in whole blood by riboflavin plus irradiation. Transfusion 53:3174-3183
85. Keil SD, Kiser P, Sullivan JJ et al (2013) Inactivation of Plasmodium spp. in plasma and platelet concentrates using riboflavin and ultraviolet light. Transfusion 53:2278-2286

86. Tonnetti L, Thorp AM, Reddy HL, Keil SD, Goodrich RP, Leiby DA (2012) Evaluating pathogen reduction of Trypanosoma cruzi with riboflavin and ultraviolet light for whole blood. Transfusion 52:409-416

87. Cardo LJ, Salata J, Mendez J, Reddy H, Goodrich R (2007) Pathogen inactivation of Trypanosoma cruzi in plasma and platelet concentrates using riboflavin and ultraviolet light. Transfus Apher Sci 37:131-137

88. Brecher ME, Hay SN (2005) Bacterial contamination of blood components. Clin Microbiol Rev 18:195-204

89. Goodrich RP, Gilmour D, Hovenga N, Keil SD (2009) A laboratory comparison of pathogen reduction technology treatment and culture of platelet products for addressing bacterial contamination concerns. Transfusion 49:1205-1216

90. Fast LD, DiLeone G, Li J, Goodrich R (2006) Functional inactivation of white blood cells by MIRASOL treatment. Transfusion 46:642-648

91. Fast LD, DiLeone $\mathrm{G}$, Cardarelli G, Li J, Goodrich R (2006) MIRASOL PRT treatment of donor white blood cells prevents the development of xenogeneic graft-versus-host disease in Rag2-/-үc-/- double knockout mice. Transfusion 46:1553-1560

92. Jackman RP, Heitman JW, Marschner S, Goodrich RP, Norris PJ (2009) Understanding loss of donor white blood cell immunogenicity after pathogen reduction: mechanisms of action in ultraviolet illumination and riboflavin treatment. Transfusion 49:2686-2699

93. Marschner S, Fast LD, Baldwin WM III, Slichter SJ, Goodrich RP (2010) White blood cell inactivation after treatment with riboflavin and ultraviolet light. Transfusion 50:2489-2498

94. Fast LD, DiLeone G, Marschner S (2011) Inactivation of human white blood cells in platelet products after pathogen reduction technology treatment in comparison to gamma irradiation. Transfusion 51:1397-1404

95. Fast LD, Nevola M, Tavares J, Reddy HL, Goodrich RP, Marschner S (2013) Treatment of whole blood with riboflavin plus ultraviolet light, an alternative to gamma irradiation in the prevention of transfusion-associated graft-versus-host disease? Transfusion 53:373-381

96. Reddy HL, Doane SK, Keil SD, Marschner S, Goodrich RP (2013) Development of a riboflavin and ultraviolet light-based device to treat whole blood. Transfusion 53:131S-136S

97. FDA Database of Select Committee on GRAS Substances (SCOGS) Reviews: Riboflavin. https:// www.fda.gov/Food/IngredientsPackagingLabeling/GRAS/SCOGS/default.htm. Zugegriffen: 22. Mai 2018

98. Diakonis VF, Grentzelos MA, Tzatzarakis MN et al (2012) Riboflavin's time-dependent degradation rate induced by ultraviolet A irradiation. Eur J Ophthalmol 22(Suppl. 7):51-56

99. Ambruso DR, Thurman $G$, Marschner $S$, Goodrich RP (2009) Lack of antibody formation to platelet neoantigens after transfusion of riboflavin and ultraviolet light-treated platelet concentrates. Transfusion 49:2631-2636

100. Janetzko K, Hinz K, Marschner S, Goodrich R, Klüter H (2009) Pathogen reduction technology (MIRASOL) treated single-donor platelets 
resuspended in a mixture of autologous plasma and PAS. Vox Sang 97:234-239

101. Li J, Goodrich L, Hansen E, Edrich R, Gampp D, Goodrich RP (2005) Platelet glycolytic flux increases stimulated by ultraviolet-induced stress is not the direct cause of platelet morphology and activation changes: possible implications for the role of glucose in platelet storage. Transfusion 45:1750-1758

102. Picker SM, Tauszig ME, Gathof BS (2012) Cell quality of apheresis-derived platelets treated with riboflavin-ultraviolet light after resuspension in platelet additive solution. Transfusion 52:510-516

103. Ostrowski SR, Bochsen L, Salado-Jimena JA et al (2010) In vitro cell quality of buffy coat platelets in additive solution treated with pathogen reduction technology. Transfusion 50:2210-2219

104. Johnson L, Winter KM, Reid S et al (2011) The effect of pathogen reduction technology (MIRA$\mathrm{SOL}$ ) on platelet quality when treated in additive solution with low plasma carryover. Vox Sang 101:208-214

105. Cookson $P$, Thomas S, Marschner S, Goodrich R, Cardigan $R$ (2012) In vitro quality of single-donor platelets treated with riboflavin and ultraviolet light and stored in platelet storage medium for up to 8 days. Transfusion 52:983-994

106. Perez-Pujol S, Tonda R, Lozano M et al (2005) Effects of a new pathogen-reduction technology (MIRASOL PRT) on functional aspects of platelet concentrates. Transfusion 45:911-919

107. Picker SM, Steisel A, Gathof BS (2008) Effects of MIRASOL PRT treatment on storage lesion development in plasma-stored apheresis-derived platelets compared to untreated and irradiated units. Transfusion 48:1685-1692

108. Picker SM, Steisel A, Gathof BS (2009) Evaluation of White Blood Cell- and Platelet-Derived Cytokine Accumulation in MIRASOL-PRT-Treated Platelets. Transfus Med Hemother 36:114-120

109. Picker SM, Oustianskaia L, Schneider V, Gathof BS (2010) Annexin V Release and Transmembrane Mitochondrial Potential during Storage of Apheresis-Derived Platelets Treated for Pathogen Reduction. Transfus Med Hemother 37:7-12

110. Castrillo A, Cardoso M, Rouse L (2013) Treatment of Buffy Coat Platelets in Platelet Additive Solution with the MIRASOL ${ }^{\otimes}$ Pathogen Reduction Technology System. Transfus Med Hemother 40:44-48

111. Zeddies S, De Cuyper IM, van der Meer PF et al (2014) Pathogen reduction treatment using riboflavin and ultraviolet light impairs platelet reactivity toward specific agonists in vitro. Transfusion 54:2292-2300

112. Galan AM, Lozano M, Molina P et al (2011) Impact of pathogen reduction technology and storage in platelet additive solutions on platelet function. Transfusion 51:808-815

113. Terada C, Mori J, Okazaki H, Satake M, Tadokoro K (2014) Effects of riboflavin and ultraviolet light treatment on platelet thrombus formation on collagen via integrin allb $\beta 3$ activation. Transfusion $54: 1808-1816$

114. Klein-Bosgoed C, Schubert P, Devine DV (2016) Riboflavin and ultraviolet illumination affects selected platelet mRNA transcript amounts differently. Transfusion 56:2286-2295

115. Feys HB, van Aelst B, Devreese K et al (2014) Oxygen removal during pathogen inactivation with riboflavin and UV light preserves protein function in plasma for transfusion. Vox Sang 106:307-315
116. Johnson L, Marks D (2015) Treatment of Platelet Concentrates with the MIRASOL Pathogen Inactivation System Modulates Platelet Oxidative Stress and NF-kB Activation. Transfus Med Hemother 42:167-173

117. Schubert $P$, Culibrk B, Coupland D, Scammell $K$, Gyongyossy-Issa M, Devine DV (2012) Riboflavin and ultraviolet light treatment potentiates vasodilator-stimulated phosphoprotein Ser-239 phosphorylation in platelet concentrates during storage. Transfusion 52:397-408

118. AuBuchon JP, Herschel L, Roger J et al (2005) Efficacy of apheresis platelets treated with riboflavin and ultraviolet light for pathogen reduction. Transfusion 45:1335-1341

119. Goodrich RP, Li J, Pieters $H$, Crookes R, Roodt J, Heyns Adu P (2006) Correlation of in vitro platelet quality measurements with in vivo platelet viability in human subjects. Vox. Sang 90:279-285

120. Macopharma (2014) Macopharma Theraflex UVPlatelets. http://blood-safety.macopharma.com/ en/category/documents-literatures/theraflexuv-platelets. Zugegriffen: 22. Mai 2018

121. Seltsam A, Müller TH (2011) UVC Irradiation for Pathogen Reduction of Platelet Concentrates and Plasma. Transfus Med Hemother 38:43-54

122. Seghatchian J, Tolksdorf F (2012) Characteristics of the THERAFLEX UV-Platelets pathogen inactivation system - an update. Transfus Apher Sci 46:221-229

123. Mohr H, Steil L, Gravemann U et al (2009) A novel approach to pathogen reduction in platelet concentrates using short-wave ultraviolet light. Transfusion 49:2612-2624

124. Thiele T, Pohler P, Kohlmann T et al (2015) Tolerance of platelet concentrates treated with UVC-light only for pathogen reduction - a phase I clinical trial. Vox Sang 109:44-51

125. Kim S, Handke W, Gravemann U et al (2018) Mitochondrial DNA multiplex real-time polymerase chain reaction inhibition assay for quality control of pathogen inactivation by ultraviolet $C$ light in platelet concentrates. Transfusion 58:758-765

126. Steinmann E, Gravemann U, Friesland M et al (2013) Two pathogen reduction technologies methylene blue plus light and shortwave ultraviolet light - effectively inactivate hepatitis $C$ virus in blood products. Transfusion 53:1010-1018

127. van der Meer PF, Gravemann U, de Korte D et al (2016) Effect of increased agitation speed on pathogen inactivation efficacy and in vitro quality in UVC-treated platelet concentrates. Vox Sang 111:127-134

128. Faddy HM, Fryk JJ, Prow NA et al (2016) Inactivation of dengue, chikungunya, and Ross River viruses in platelet concentrates after treatment with ultraviolet C light. Transfusion 56:15481555

129. Seltsam A (2011) Pathogenreduktion mittels UVC-Licht: Entwicklung des THERAFLEX UVPlättchen-Systems. DGTI, Freiburg. https://www. dgti.de/docs/doclink/10802/6.\%20Vortrag\%20 Seltsam,\%20Theraflex\%20UV\%20Platelets.pdf. Zugegriffen: 23. Mai 2018

130. Gravemann U, Schmidt JP, Tolksdorf F et al (2013) Influenza A virus H3N2 is efficiently inactivated by the THERAFLEX UV-PLATELETS system. Vox Sang 105(Suppl. 1):134

131. Fryk JJ, Marks DC, Hobson-Peters J et al (2017) Reduction of Zika virus infectivity in platelet concentrates after treatment with ultraviolet $\mathrm{C}$ light and in plasma after treatment with methylene blue and visible light. Transfusion 57:2677-2682

132. Gravemann U, Lambrecht B, Schmidt J-P, Seltsam A (2014) Hepatitis A virus is efficiently inactivated by the THERAFLEX UV-Platelets system. Vox Sang 107(Suppl. 1):128

133. Spindler-Raffel E, Benjamin RJ, McDonald CP et al (2017) ISBT Working Party Transfusion-Transmitted Infectious Diseases (WP-TTID), Subgroup on Bacteria (2017) Enlargement of the WHO international repository for platelet transfusionrelevant bacteria reference strains. Vox Sang 112:713-722

134. Gravemann U, Tolksdorf F, Handke W, Müller TH, Seltsam A (2017) The THERAFLEX UV-Platelets technology efficiently inactivates transfusion-relevant bacteria species in contaminated platelet concentrates. Transfusion 57(Suppl. 1):203

135. Castro E, Girones N, Guerrero N, Barea L, Fresno $M$ (2008) The effectiveness of UVC pathogen inactivation system on reducing the Trypanosoma cruzi and Leishmania infantum burden in platelets. Vox Sang 95(Suppl. 1):290

136. Castro E, González LM, Bautista JM, Montero E, Rubio JM (2013) The efficacy of UVC pathogen inactivation on the reduction of Plasmodium falciparum in buffy coat derived platelets. Vox Sang 105(Suppl. 1):133

137. Castro E, González LM, Rubio JM, Ramiro R, Gironés N, Montero E (2014) The efficacy of the ultraviolet $C$ pathogen inactivation system in the reduction of Babesia divergens in pooled buffy coat platelets. Transfusion 54:2207-2216

138. Pohler P, Müller M, Winkler C et al (2015) Pathogen reduction by ultraviolet $C$ light effectively inactivates human white blood cells in platelet products. Transfusion 55:337-347

139. Pohler P, Lehmann J, Veneruso V et al (2012) Evaluation of the tolerability and immunogenicity of ultraviolet C-irradiated autologous platelets in a dog model. Transfusion 52:2414-2426

140. Bashir S, Cookson P, Wiltshire M et al (2013) Pathogen inactivation of platelets using ultraviolet $C$ light: effect on in vitro function and recovery and survival of platelets. Transfusion 53:990-1000

141. Tynngard N, Trinks M, Berlin G (2015) In vitro function of platelets treated with ultraviolet $C$ light for pathogen inactivation: a comparative study with non irradiated and gamma-irradiated platelets. Transfusion 55:1169-1177

142. Van Aelst $B$, Devloo R, Vandekerckhove $P$, Compernolle V, Feys HB (2015) Ultraviolet C light pathogen inactivation treatment of platelet concentrates preserves integrin activation but affects thrombus formation kinetics on collagen in vitro. Transfusion 55:2404-2414

143. Martini R, Kempfer CB, Rodrigues Mde A et al (2010) Bacterial contamination on platelet concentrates: identification, antimicrobial susceptibility profile and transfusion-related sepsis. Rev Soc Bras Med Trop 43:682-685

144. Kou Y, Pagotto F, Hannach B, Ramirez-Arcos S (2015) Fatal false-negative transfusion infection involving a buffy coat platelet pool contaminated with biofilm-positive Staphylococcus epidermidis: a case report. Transfusion 55:2384-2389

145. Snyder E, Raife T, Lin L et al (2004) Recovery and life span of 111 indium-radiolabeled platelets treated with pathogen inactivation with amotosalen $\mathrm{HCl}$ (S-59) and ultraviolet A light. Transfusion 44:1732-1740 
146. Murphy S (2004) Radiolabeling of PLTs to assess viability: a proposal for a standard. Transfusion 44:131-133

147. FDA Blood Products Advisory Committee (2004) July 22-23th, Summary Topic II: New Standards for Platelet Evaluation. https://wayback.archiveit.org/7993/20170404063056/https://www.fda. gov/ohrms/dockets/ac/04/transcripts/20044057t1.htm. Zugegriffen: 23. Mai 2018

148. Swiss Medic Haemovigilance Annual report 2015. www.swissmedic.ch/haemovigilancereport. Zugegriffen: 23. Mai 2018

149. Butler C, Doree C, Estcourt LJ et al (2013) Pathogen-reduced platelets for the prevention of bleeding. Cochrane Database Syst Rev 3:CD9072

150. Estcourt LJ, Malouf R, Hopewell S et al (2017) Pathogen-reduced platelets for the prevention of bleeding. Cochrane Database Syst Rev 7:CD9072

151. McCullough J, Vesole DH, Benjamin RJ et al (2004) Therapeutic efficacy and safety of platelets treated with a photochemical process for pathogen inactivation: the SPRINT Trial. Blood 104:1534-1541

152. Kerkhoffs JLH, van Putten WLJ, Novotny VMJ et al (2010) Clinical effectiveness of leucoreduced, pooled donor platelet concentrates, stored in plasma or additive solution with and without pathogen reduction. Br J Haematol 150:209-217

153. Cid J, Escolar G, Lozano M (2012) Therapeutic efficacy of platelet components treated with amotosalen and ultraviolet A pathogen inactivation method: results of a meta-analysis of randomized controlled trials. Vox Sang 103:322-330

154. Garban F, Guyard A, Labussière H et al (2018) Comparison of the Hemostatic Efficacy of Pathogen-Reduced Platelets vs Untreated Platelets in Patients With Thrombocytopenia and Malignant Hematologic Diseases: A Randomized Clinical Trial. JAMA Oncol 4:468-475

155. The MIRASOL Clinical Evaluation Study Group (2010) A randomized controlled clinical trial evaluating the performance and safety of platelets treated with MIRASOL pathogen reduction technology. Transfusion 50:2362-2375

156. Snyder E, McCullough J, Slichter SJ et al (2005) Clinical safety of platelets photochemically treated with amotosalen $\mathrm{HCl}$ and ultraviolet $\mathrm{A}$ light for pathogen inactivation: the SPRINT trial. Transfusion 45:1864-1875

157. Kleinman S, Reed W, Stassinopoulos A (2013) A patient-oriented risk-benefit analysis of pathogen-inactivated blood components: application to apheresis platelets in the United States. Transfusion 53:1603-1618

158. Amato $M$, Schennach $H$, Astl $M$ et al (2017) Impact of platelet pathogen inactivation on blood component utilization and patient safety in a large Austrian Regional Medical Centre. Vox Sang 112:47-55

159. Knutson F, Osselaer J, Pierelli L et al (2015) A prospective, active haemovigilance study with combined cohort analysis of 19,175 transfusions of platelet components prepared with amotosalen-UVA photochemical treatment. Vox Sang 109:343-352

160. Jutzi M, Rüesch M, Taleghani BM (2013) Einführung der Pathogeninaktivierung für Thrombozytenkonzentrate in der Schweiz. Schweiz Med Forum 13:222-226 